Wilder, Gärtner, Bierwisch (eds.) The Role of Economy Principles in Linguistic Theory, Berlin: Akademie Verlag 1997, p. 227-266

Manfred Bierwisch

\title{
Lexical Information from a Minimalist Point of View
}

\section{Introduction}

Simplicity as a methodological orientation applies to linguistic theory just as to any other field of research: 'Occam's razor' is the label for the basic heuristic maxim according to which an adequate analysis must ultimately be reduced to indispensible specifications. In this sense, conceptual economy has been a strict and stimulating guideline in the development of Generative Grammar from the very beginning. Halle's (1959) argument discarding the level of taxonomic phonemics in order to unify two otherwise separate phonological processes is an early characteristic example; a more general notion is that of an evaluation metric introduced in Chomsky $(1957,1975)$, which relates the relative simplicity of alternative linguistic descriptions systematically to the quest for explanatory adequacy of the theory underlying the descriptions to be evaluated. Further proposals along these lines include the theory of markedness developed in Chomsky and Halle (1968), Kean $(1975,1981)$, and others, the notion of underspecification proposed e.g. in Archangeli (1984), Farkas (1990), the concept of default values and related notions. An important step promoting this general orientation was the idea of Principles and Parameters developed in Chomsky $(1981,1986)$, which reduced the notion of language particular rule systems to universal principles, subject merely to parametrization with restricted options, largely related to properties of particular lexical items. On this account, the notion of a simplicity metric is to be dispensed with, as competing analyses of relevant data are now supposed to be essentially excluded by the restrictive system of principles.

Extending this development by a further important step, the Minimalist Program initiated in Chomsky $(1992,1994)$ set out to dispense with stipulated aspects of the Principles and Parameters view, deriving the properties of the language capacity as far as possible from conditions that appear to be conceptually necessary or can be reduced to general requirements of cognitive capacities. This restricts, on the one hand, assumptions about the organization of language to what appears to be the conceptual minimum, and constrains, on the other hand, representational means and computational operations according to conditions of economy.

The general view corresponding to this development raises a number of interesting and by no means trivial problems. First, to the extent to which general principles of conceptual parsimony as well as representational and computational economy are supposed to determine the structure of possible languages (or rather systems of linguistic knowledge), the methodological maxim of simplicity appears to be turned into a basic characteristic of the actual subject matter. In other words, the maxim "Minimize x", taken as a short-hand characterization of the Minimalist Program, 
becomes the organizing principle of the language faculty. Second, to the extent to which principles of the language faculty reduce to more general conditions of cognitive capacities, properties of linguistic knowledge need not be stipulated, but are explained by independently given principles. However, by the same token the autonomy of the language faculty, strongly advocated so far in the tradition of Generative Grammar, cannot be preserved in its strict sense, even though some sort of indirect autonomy, relying on the specific boundary conditions, might be a reasonable account of the relevant observations. I will briefly touch this point in section 2.

Without taking a particular position with respect to these questions, I will explore here some issues the minimalist orientation raises for the organization of lexical information. Although I will not commit myself to specific technical assumptions associated with particular versions of the Minimalist Program, a number of issues clearly fall in place under a fairly broad view of conceptual parsimony and representational economy. Two interrelated perspectives seem to be indicated in this respect: a) consequences of the minimalist orientation for the content and organization of lexical information, and b) conditions which the role of lexical information imposes on other aspects of the Minimalist Program. Obviously, these perspectives lead to a number of more specific problems, which will be taken up in turn. The paper is organized as follows: section 2 outlines the general framework within which the role of lexical information is to be determined; section 3 discusses the types of information lexical entries must accommodate and the general organization of entries thence emerging; section 4 is concerned with conditions economizing lexical entries with respect to syntactic and semantic information; section 5 discusses some consequences for the combinatorial aspect of the language capacity; and section 6 indicates provisional consequences.

\section{Lexical Information and the Organization of Language}

I will be concerned with language in the sense of I-Language characterized in Chomsky (1986 and related work), referring to the Grammar $G_{\llcorner}$as the knowledge determining a particular I-Language L, with Universal Grammar UG being the basic structure from which different I-Lanaguages emerge according to appropriate experience. I will assume, in particular, that G includes the Lexical System LS, i.e. the linguistically determined aspects of lexical knowledge. These matters will be made more precise as we proceed.

I-Language relates the structure of expressions to conceptual interpretations -intuitively speaking, it defines a correspondence between sound and meaning. Using the terminology proposed in Chomsky (1991 and later work), these domains are organized by the Articulatory-Perceptual System A-P, and the Conceptual-Intentional System C-I, respectively. A-P and C-I are to be considered as mental systems that are accessed or recruited by the language capacity, although they are subject to their own, extralinguistic principles and constraints. ${ }^{1)}$ More specifically, A-P determines the motoric and perceptual patterns in terms of which signals are processed, a conceptually necessary dimension of which is given by their temporal organization. $\left.{ }^{2}\right)$ $\mathrm{C}$-I on the other hand integrates various subsystems in terms of which experience is conceptually organized and intentional relations to the (external and internal) environment are established. Without going into the complex and at best partially 
understood problems of this domain, some sort of functor-argument (or operatoroperand) structure seems to be indispensible as a representational format, requiring hierarchical organization, but no intrinsic linear ordering. The correspondence ILanguage establishes between these two domains has a number of prerequisites.

First, I-language must provide a matching between patterns or configurations in A-P and $\mathrm{C}-\mathrm{I}$, it must hence provide interfaces with these domains. Following Chomsky (1993), I will call these interfaces Phonetic Form PF and Logical Form LF, respectively. The structure of PF and LF must be compatible (but not identical) with that of the domains they interface with. This has, of course, at least restricting consequences for the nature of PF and LF, given the different conditions inherent in A-P and C-I.

Second, as the form of expressions and their meaning cannot in general be mapped onto each other by way of analogy, the correspondence between PF and LF defined by the Grammar G requires PF and LF to be organized in terms of configurations of discrete primes or basic dimensions. In other words, both PF and LF must have properties of an abstract algebraic system. This leads to the following general schema, which indicates basic conceptual requirements: ${ }^{3)}$

Expression

644474448
Content

$$
644474448
$$

$$
\text { A-P } \quad<===\quad \text { PF } \underset{1442443}{\longrightarrow} \text { LF } \quad<===>\text { C-I }
$$

I-Language

This schematization should not be taken to stipulate four separate levels or systems of representation. PF and LF are rather to be construed as interfaces between two systems, viz. A-P and $G$, and $C-I$ and $G$, respectively. In other words, PF and LF recruit configurations of $A-P$ and $C-I$ according to the conditions of $G$, somewhat like pixels drawing on continuous shades or values. ${ }^{4)}$

Third, as the correspondence between A-P and C-I is not based on structural analogy, but is arbitrary in the Saussurean sense, the relation between PF and LF furthermore requires a list of fixed connections established between configurations of the two domains. These connections constitute the lexical items of a given ILanguage, the Lexical System LS thus being a conceptually necessary aspect of the language capacity. ${ }^{5)}$ Following Levelt (1989), I will call the PF-component of a lexical item its Lexeme, the LF-component its Lemma.

Fourth, as the correspondence between sound and meaning is defined over a potentially infinite range, $\mathrm{G}$ must provide a compositional mapping, based on a recursive, combinatorial structure for PF, LF, and their correspondence. It is only by means of this combinatorial capacity provided by UG - drawing perhaps on general cognitive principles - that the actual range of I-Language is established. ${ }^{6)}$ The important point to note here is the fact that the combinatorial structure of $G$ has crucial consequences for - or rather preconditions in - the organization of lexical entries, which must intrinsically be disposed for combinatorial operations, a matter to which we will return in more detail. 
To sum up, the following assumptions seem to be necessary:

(2) (a) I-Language must provide two interface levels PF and LF based on discrete primitive elements, the interpretation and arrangement of which are in part determined by the properties of A-P and C-I, respectively, the systems they interface with;

(b) I-Language must contain a system LS of lexical items connecting lexemes and lemmas pertaining to PF and LF, respectively;

(c) I-Language must be based on recursive combinatorial operations that define the organization and correspondence of PF and LF over a potentially infinite range.

The content of these requirements must be spelled out in several respects, in part according to purely conceptual conditions, in part with respect to empirical constraints. As to PF, the following assumptions will be made: The basic elements are features, assigned to tiers and linked to segments, in terms of which the linear ordering mentioned earlier is organized. In accordance with their feature structure, segments constitute syllables, which are grouped into larger prosodic units. ${ }^{7)}$ As to LF, the nature of basic elements is controversial and will be taken up in section 3 . They must be taken, in any case, as elements that are to be interpreted in C-I, hence representing conceptual units, combining with each other in terms of functorargument relations. This suggests that elements of LF are assigned to types or categories in the sense of Ajdukiewicz (1935), defining automatically the type of complex configurations. ${ }^{8)}$ I will furthermore assume that LF - just as C-I - is not based on linear ordering, which means that all structural relations must be hierarchical in nature. It follows that functors of LF must all be of the nature indicated in (3):

(3) If $\alpha$ and $\beta$ are categories, then $(\alpha / \beta)$ is a complex category.

$\alpha$ and $\beta$ might be complex or basic - where basic types may be e.g. 1 for individual concepts and 0 for propositions - such that a two-place relation like the concept HAVE is of type (0/1)/1. On these assumptions, the following claim about LF comes as a logical consequence:

(4) Representations of LF are strictly binary branching structures imposed on primitive elements.

It follows that familiar notions like dominance, c-command immediately apply to LF as characterized by (4). I will have to say more about the nature of LF as we proceed.

Entries of the lexical system must participate in the representational systems PF and LF and could hence be characterized by ordered pairs of the following general format:

$<\mathrm{PF}_{\mathrm{LE}}, \mathrm{LF}_{\mathrm{LE}}>$ where $P F_{L E}$ and $L F_{L E}$ determines the contribution of the element $L E$ to $P F$ and LF, respectively. 
Both $P F_{L E}$ and $L F_{L E}$ will have to be redundancy free or underspecified in accordance with pertinent principles of economy to be taken up below. I will furthermore revise (5) by splitting up the information to be subsumed under LF $F_{L E}$ for reasons to be discussed immediately.

According to the Minimalist Program the architecture summarized in (2) is not only necessary, but also sufficient in the sense that there is no further level of representation between PF and LF; in other words, the combinatorial operations mentioned in (2c) are not supposed to require independent levels of representation with systematic properties except the interface levels LF and PF. This is a strong and by no means obvious assumption related to both empirical and conceptual considerations, which raises non-trivial questions concerning the status of syntactic representations. The point to be noted is, that Logical Form, although explicitly related to the conceptual interpretation, has always been understood in Generative Grammar as a level of syntactic representation. This holds explicitely for e.g. Chomsky (1981), but has not changed within the Minimalist Program, where LF is in fact considered as the only level of syntactic representation, which at the same time, however, specifies all that I-Language determines with respect to semantic interpretation.

The problem with this double nature of LF emerges, if we consider the following two economy principles which play a crucial role within the Minimalist Program:

(6) Representational economy: Representations in PF and LF must not retain specifications that are not interpretable in the respective performance systems A-P and C-I. (Principle of Full Interpretation FI)

(7) Derivational economy: The mapping between LF and PF is based on the least computational expense.

Economy as specified in (6) and (7) goes beyond parsimonious conceptual necessity as summarized in (1); it may in fact lead to alternative realizations (concerning e.g. the number or complexitiy of computational steps), and there is, in any case, a tension between the two principles: elements that merely regulate the computational mapping between PF and LF, but are uninterpretable in A-P and C-I, are by virtue of FI either completely excluded or else must be eliminated from LF and PF by additional operations in conflict with (7). ${ }^{9)}$ The actual assumption is, of course, that ILanguage relies crucially on strictly grammatical, uninterpretable features that are to be deleted at the interface levels. Hence economy can only be realized as the balance between (6) and (7) (and possibly other principles). I will return to the issue in section 3.

\section{The Content and Organization of Lexical Entries}

Returning to the general schema (5), I will assume that there is no principled controversy about the nature of $\mathrm{PF}_{\mathrm{LE}}$, a complex configuration of the level PF with all information omitted that follows from general rules or principles of $\mathrm{G}$, in other words, an underspecified representation in the sense explored in Archangeli (1984), Steriade (1987) and related work, indicating LE's contribution to PF. ${ }^{10}$ ' Technical details aside, the notion of underspecification belongs to the traditional orientation 
towards economy mentioned above, obviously to be incorporated into more recent conceptions of Minimalism. Things are less clear with respect to LF $F_{L E}$, where there seem to be at least two attitudes, one of which takes LF $F_{L E}$ to be in general a primitive element of I-Language with respect to its interpretation in C-I, while the other considers it as essentially compositional, built up from more primitive elements that represent conditions of $\mathrm{C}-\mathrm{I}$. For the sake of discussion, I will call the former attitude the global view, and the latter the compositional view of LF $F_{L E}$. Even though the contrast between these two views appears to be clear enough, it is often not obvious how it applies to actual proposals.

Consider in this respect the Lexical Relational Structure LRS discussed by Hale and Keyser (1993), who on the one hand seem to endorse the global view, assigning no internal structure to basic lexical items, but who allow these items on the other hand to combine by incorporation into complex items. The issue can be illustrated by location verbs like shelve, box, house, etc. which Hale and Keyser suppose to be parallel to put in the sense indicated in (8)(a) and (b) based on something like (9)(a) and (b) as the respective verb phrases resulting from Head Movement:

(8) (a) She put her books on the shelf.

(b) She shelved her books

(9) (a) [

(b) $[\text { [ [ [ shelf }]_{\mathrm{i}}$ ON $]_{\mathrm{j}}$ PUT $]_{\mathrm{k}}$

[ put ]k

[ her books [ $t_{k}$ [ on [ the shelf ] ] ] ] [her books [ $\left.\left.t_{k}\left[\begin{array}{llll} & t_{j} & {[} & t_{i}\end{array}\right]\right]\right]$

ON and PUT are meant to indicate the LF $F_{L E}$ of on and put, respectively, assuming that these enter the construction of $(8 b)$ without contributing a $P F_{L E}$ for the application of Spell Out. Hale and Keyser argue that along these lines the assumption of abstract - i.e. phonetically empty - verbs like put (for location verbs) or provide (for locatum verbs like saddle, paint, etc), make (for result verbs like clear, open, etc.), together with independently motivated and constrained operations like Head Movement, accounts for crucial properties of possible lexical items and their behavior. There are various problems with this analysis, which I need not discuss here. ${ }^{11)}$ The main point to be noted is the fact that alongside with the operations of prelexical syntax there must be lexical entries like (10):

$$
\begin{array}{cc}
</ \text { shelve/ }, & {[\mathrm{v}[\mathrm{P}[\mathrm{N} \text { SHELF }][\mathrm{P} \text { ON }]][\mathrm{v} \text { PUT }]]>} \\
\mathrm{PF}_{\mathrm{LE}} & \mathrm{LF}_{\mathrm{LE}}
\end{array}
$$

SHELF indicates the $L_{L E}$ of the incorporated noun shelf. Entries like (10) are necessary, as it is an idiosyncratic, lexical fact whether or not the incorporating verb for a given noun or adjective exists, and which abstract verb it supplies: chair has the put- and the provide-variant, saddle has only the provide-variant, ship only the putvariant, and basket has neither. To conclude, the LRS-approach of Hale and Keyser eventually leads to assume a compositional $L F_{L E}$ for the lexical items under discussion, in order to account for the grammatical properties of these elements. I will return to this point shortly.

Looking at Jackendoff's $(1990,1994)$ Lexical Conceptual Structure LCS, which is programmatically compositional, we notice a different problem. Jackendoff assumes on the one hand that his level of Conceptual Structure CS is not part of linguistic 
knowledge, but rather provides the central representational system of language independent conceptual organization, i.e. of $\mathrm{C}-\mathrm{I}$ in the terminology adopted here. On the other hand, he considers LCSs as part of lexical items, which clearly belong to linguistic knowledge, but also as pertaining to CS, which is clearly not part of linguistic knowledge. Jackendoff furthermore assumes that lexical items, which he considers as rules defining (in part) the correspondence between Conceptual and Phonological Structure of linguistic expressions, comprise syntactic besides phonological and conceptual information. ${ }^{12)}$ Yet another view, which draws or skips the boundary between linguistic and conceptual knowledge in different ways, is embodied in Pustejovsky's (1995) conception of lexical information. Like Jackendoff, Pustejovsky clearly endorses a compositional view, but to what extent he considers the compositionality as part of I-Language or rather as a matter of general conceptual structure, is unclear in crucial respects.

It seems to me useful in view of these and other problems, to which I will turn immediately, to split up LF $F_{L E}$ into two components, replacing the schema (5) by (11), where the Semantic Form SF constitutes the interface with $\mathrm{C}$-I in the narrower sense, while the Grammatical Form GF comprises the syntactic and morphological information not to be interpreted outside I-Language.

$$
<\mathrm{PF}_{\mathrm{LE}}, \quad<\mathrm{GF}_{\mathrm{LE}}, \quad \mathrm{SF}_{\mathrm{LE}}>>
$$

So far, this revision of (5) does not necessarily deviate from the Minimalist assumption that there is no level besides PF and LF, as the separation of GF and SF need not be construed as introducing an additional representational system, but merely as a systematic distinction within one level of representation. This can be illustrated by means of a revised version of (10):

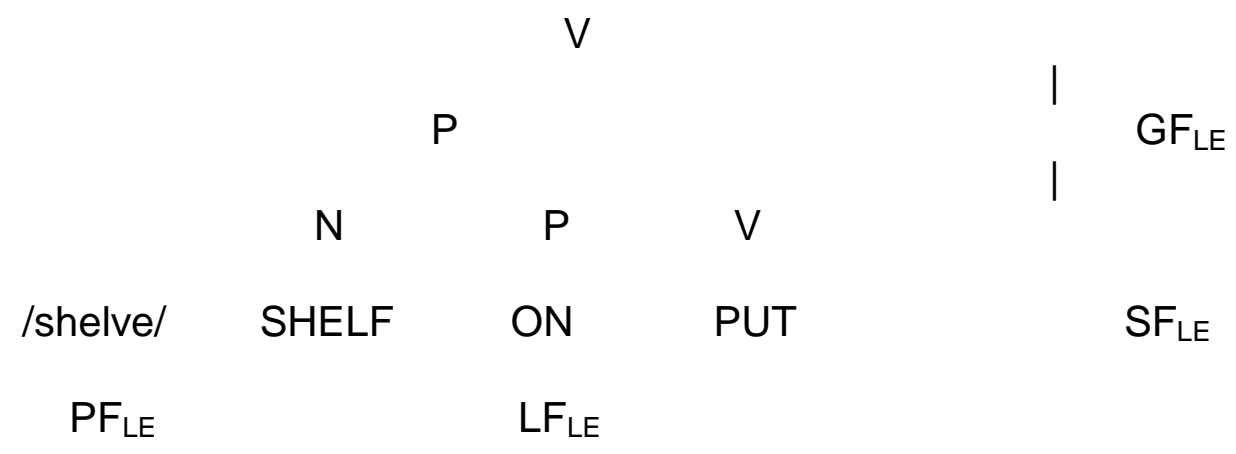

The distinction between GF and SF comes close to the problem traditionally conceived as the relation between syntax and semantics, if one considers semantics as concerned with the conceptual interpretation of language, just as phonology is concerned with its articulatory and auditory interpretation. ${ }^{13)}$ Formally, the distinction appears to correspond to that between non-terminal and terminal nodes of LF as indicated in (11), a plausible view to start with, but one that has to be revised on closer inspection. What is at issue, besides the status of the 'sublexical components', is the nature of syntactic categories or rather the grammatical features defining them. The issue comes in two ways.

Consider first syntactic categories like V, N, P or D and C, and their projections, which are specified by syntactic features like $[+\mathrm{N}, \pm \mathrm{V}, \ldots]$. According to the principle of Full Interpretation $\mathrm{FI}$, interface representations must not contain material 
uninterpretable in the respective interpretive systems. This leaves apparently only one of two options: either category features like $\mathrm{N}, \mathrm{V}$ etc. belong to the interface and must be interpreted in C-I by appropriate specifications, or they cannot be interpreted and must hence be excluded from the interface.I don't consider the conceptual interpretation of features like $\mathrm{V}, \mathrm{N}$ etc. as a serious option, even if one were to resort to abstract ontological categories like entity, state, property or something similar. Ontological interpretation of syntactic categories has repeatedly been shown to be misguided. Hence the features in question must either be deleted before FI applies, or not belong to the interface level in the first place. In separating SF as an interface in the narrower sense from GF as the language internal aspect of LF, we adopt the latter option. One might think of a third alternative, according to which syntactic categories reduce to reflexes of semantic (or rather conceptual) types, like proposition, one-place predicate, n-place functor, etc., i.e. inherent properties of legitimate, interpretable interface elements of the sort defined in (3) above as a conceptually necessary condition of the interface, with no independent status assigned to them. ${ }^{14)}$ But that is obviously not the status of category features distinguishing e.g. V, N, C, which capture computational properties independently of conceptual types. Thus syntactically, items like sleep, jump,call, etc.must alternatively be assigned to the category $\mathrm{N}$ or $\mathrm{V}$, even though their conceptual type remains the same. This observation does not exclude nontrivial correspondences between syntactic and conceptual categories - as we will see immediately; it clearly shows, however, that the former cannot be reduced to the latter, but must be specified in their own right.

The second issue to consider concerns morphosyntactic features specifying Case, Gender, Person, etc. Here the problem appears to be the inverse of the one just discussed: morphosyntactic features are supposed not to appear in interface representations because they would violate FI. Most - if not all ${ }^{15)}$ - of them do have a conceptual interpretation, however: Tense and Aspect relate to conditions on temporal structure, Number relates to cardinality, Person to participation in the communicative event, etc. Besides this apparent conflict - prohibition of interpretable features at the interface - there are at least two further problems to recognize.

First, several of the categories specified by the features in question obviate the conceptual interpretation under various, partially idiosyncratic conditions. Thus, plurale tanta suppress cardinality, inanimates obviate the sex interpretation of Gender, notional Case is frequently devoid of conceptual content, etc. Those instances of features must obviously be excluded from the interface level.

Second, within the Minimalist Program, morphosyntactic features are supposed to show up pairwise and must be checked against each other in order to delete, i.e. to disappear from the interface representation. Thus the Tense features of the Verb must be matched by those of $\mathrm{T}^{0}$, the Case feature of the Verb must be matched by those of a DP, etc. The checking is bound to particular configuations that are assumed to result from movement of one of the features (together with the whole constituent carrying the feature). Irrespective of the metaphor of Movement and Checking, it is obvious that only one of the features - either the moving or the target feature - is related to conceptual interpretation, while the other is not. ${ }^{16)}$

To sum up, morphosyntactic features, which originate in lexical information of the items carrying them, must in principle be susceptible to conceptual interpretation at 
the interface level, even though this cannot hold for all instances of them. Hence whether conceptual content is associated with a morphosyntactic feature, and if so which, must be specified in the lexical items in appropriate way.

From these considerations, the following conclusions emerge:

First, both syntactic and morphological categories are characterized by features that must be represented in lexical items. While for morphological categories these features are susceptible to (and possibly based on) conceptual interpretation, this does not hold for all instances of them, and it does not include syntactic categories. Hence morphosyntactic categorization comprises lexical information that must not be part of the interface level, i.e. of SF in terms of the present proposal. Whether the component GF, which contains this information, is bound to a separate level of representation beyond the interface levels, will be left open for the moment.

Second, information that belongs to GF must be specified according to its status, categorization and subcategorization in traditional terms, Head-features and Phrasal features in more recent frameworks. Before I look at this problem in somewhat more detail, one further aspect of syntactic information has to be considered, viz. the nature of $\theta$-Roles or Argument Positions and their relation to the basic components of SF. Let me return to this effect to the entry given in (12).

A minimal assumption implicit in the analysis of shelve and the equivalence illustrated in (8) requires put to provide Argument Positions for the Agent (= SubjectDP), the Theme (= Object-DP) and the Goal (= directional PP), with Agent and Theme inherited by shelve. Using the parenthesis notation proposed in Grimshaw (1990) to indicate the hierarchy of Argument Positions, we get the following Argument Structures:

(13) (a) /put/

(b) /shelve/

( Agent (Theme ( Goal )))

( Agent (Theme))

There is little doubt that syntactic argument positions are closely related to and essentially determined by the possible conceptual interpretation of the lexical items they belong to. This can be made explicit in various ways. I will take up here proposals developed in Bierwisch (1988), Wunderlich (1991) and related work, where Argument Positions are represented by abstractors operating over variables in the SF-component of lexical items. Thus, instead of just adding (13b) to the entry sketched in (12), we would get something like (14), where $\lambda x$ and $\lambda y$ correspond to Agent and Theme of (13), respectively:

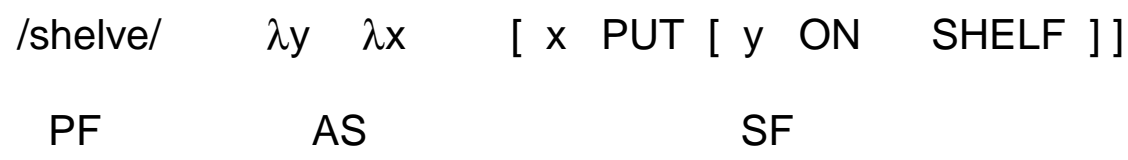

The SF-component in (14) differs from that in (12) by the addition of the variables $x$ and $y$, indicating the position for the actor of the predicate PUT and the theme of the relation ON. The elements PUT, ON, etc. are to be interpreted in C-I and might be specified with respect to their type according to the type system indicated in (3) in roughly the following way: 


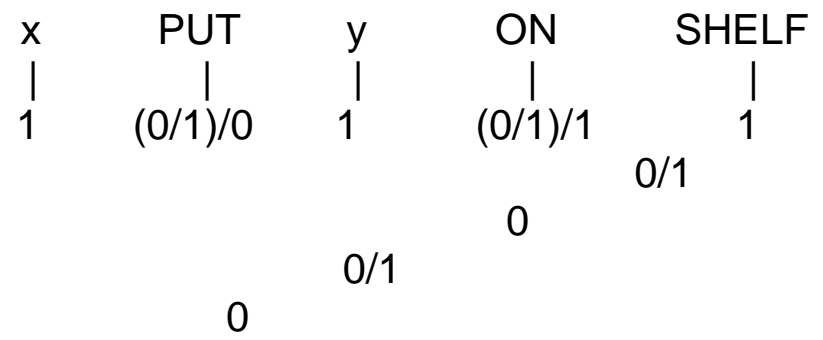

This is a simplification in various respects ${ }^{17)}$, but it nevertheless allows two generalizations to be indicated. First, the basic elements of SF - which are either constants like ON, PUT, etc. or variables $x, y, z$, etc. - are ranked relative to each other in terms of the functor-argument relation. This can be made explicit by means of the following definition:

(16) $X$ a-commands $Y$ in $Z$ iff

(a) $X^{\prime}$ is the argument of the functor $Y^{\prime}$ in $Z$, and

(b) $X$ and $Y$ are (proper or improper) parts of $X^{\prime}$ and $Y^{\prime}$, respectively.

According to (16) an argument-expression $X^{\prime}$ and all its (imporper) parts argumentcommand the functor $Y^{\prime}$ (and all its parts) that applies to it. Thus in $Z=(15), x$ acommands [PUT [y ON SHELF] ], and hence $x$ also a-commands $y$, just as the argument [y ON SHELF] - and hence also its part y - a-commands PUT. The ranking thus defined will be put touse directly Second, the SF of major lexical categories can be assumed to belong to a highly restricted range of possible types; canonically, they are of type 0 , i.e. they specify a propositional condition on conceptual interpretation. The apparent deviation, according to which e.g. shelve is is to be considered as a two-place relation, is due to the argument positions $\lambda x$ and $\lambda y$, as indicated in (14).

The next point to be taken up concerns the ordering of the lambda operators in the Argument Structure AS. This ordering reflects the hierarchy of the Theta-Roles: the Theme $\lambda y$ is the lower role that must be applied first, the Agent $\lambda x$ is the higher role to be applied only after $\lambda y$. This ranking is directly determined by the ranking of pertinent variables in SF via the following principle:

(16) $\lambda y$ is subordinate to (i.e. precedes) $\lambda x$ in AS, if $x$ a-commands $y$ in SF.

Intuitively, the effect of (16) is to project the ranking of variables in SF into syntactic relations defined in terms of c-command. Actually, (16) is in need of certain refinements that need not concern us here.

So far, the Argument Structure defines what Chomsky (1986) called s-selection, i.e. the subcategorization of lexical items related to their semantic or conceptual properties represented in SF. The way in which this aspect is represented here explicitly relies on the notion that the head-complement relation in syntax corresponds semantically to functional application. In other words, combining a lexical head with its syntactic complement amounts to specifying the variable bound by the argument position by means of the information provided by the complement, thereby eliminating the argument position according to the standard operation of lambda conversion. 
With this background let me return to the problem of morpho-syntactic features to be associated with lexical entries. I will discuss these features in terms of the traditional distinction between categorization and subcategorization, where the latter boils down to what Chomsky (1986) calles c-selection. To begin with, categorization in terms of syntactic features like $[\alpha \mathrm{V}],[\beta N]$, morphological features specifying Case, Number, Gender, etc. might simply be represented as a set of formal features in the usual way, extending e.g. (14) to something like (17):

$$
\text { /shelve/ } \quad[+\mathrm{V},-\mathrm{N}, \ldots] \quad \lambda \mathrm{x} \quad \lambda \mathrm{y}
$$

Several issues arise with respect to this part of $\mathrm{GF}_{\mathrm{LE}}$, in particular the question of which features may show up, and how they are to be interpreted. These will be discussed in connection with the features specifying subcategorization with respect to c-selection in the sense of Chomsky (1986), to which I will turn next.

C-selection is incumbent on s-selection, adding predictable or idiosyncratic conditions regarding the morpho-syntactic realization of semantically licensed arguments ${ }^{18)}$. The minimal assumption to account for this relation is to associate features of c-selection with their respective lambda operators. In other words, an argument position in AS is an ordered pair $\langle\lambda x, F>$, where $F$ represents the formal conditions imposed on arguments to be theta-marked by $\lambda x$. In this sense, (17) might provisionally be completed as in (18), with [Acc] and [Nom] indicating Casefeatures to be matched by the Object and Subject, respectively:

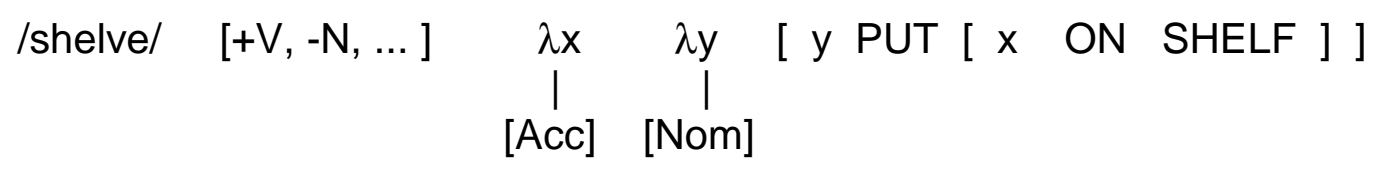

C-selection features (c-features, for short) are to a large extent structurally predictable and must not be lexically specified, as we will see shortly. What should be clear, however, is their combinatorial effect. Essentially, c-features specify the properties a lexical head $X$ imposes on the morpho-syntactic categorization of its complements $Y_{1}, \ldots, Y_{k \cdot}{ }^{19)}$ If these conditions are met, $X$ stepwise merges with $Y_{j}$ into the complex $\left.\left[\begin{array}{ll}X & Y_{1}\end{array}\right] \ldots Y_{k}\right]$ or $\left[Y_{k} \ldots\left[\begin{array}{ll}Y_{1} & X\end{array}\right]\right]$ for $k \geq i \geq 1$. At each step, one argument position is saturated by functional application and disappears from the Argument Structure. ${ }^{20)}$ Thus, c-features must be matched by the category features of the argument for the Theta-role to be assigned. It follows that all c-features must in principle also occur in the categorization part of $\mathrm{GF}_{\mathrm{LE}}$. Although this does not imply that the converse also holds, the simplest assumption is that categorization and subcategorization rely on the same possible features. Their actual choice is a matter of each particular G - or rather its Lexical System.

This leaves us with the question of how formal features are interpreted. This question has two parts. One part concerns their role as formal features in the computational system of language. The matching between categorization and c-selection belongs to this aspect, and we will have to say more about it in section 4. Crucially, feature matching is completely neutral with respect to possible conceptual interpretation. Not only do features like [Masculine] or [Plural] in e.g. German Tisch (table) or Ferien (vacation), respectively, not correspond to the expected interpretation, but also more systematically by the fact, that features specifying agreement conditions like 
Person or Number must not be interpreted twice, even though agreement requires them by definition to start out in two different positions.

The other part of the issue concerns the conceptual interpretation which may nevertheless be associated with formal features. This interpretation must obviously be separate from, but still related to their status as formal elements, and the relation must not be arbitrary in the sense in which e.g. PF and SF are related in a lexical entry. To put it the other way round: features for Gender, Number, Person etc. are based on elements of SF, which are taken up by the computational system according to conditions that are independent from the conceptual interpretation. How this relation is to be represented appropriately, is anything but obvious. Instead of making inconclusive proposals, I will merely indicate two of the various types of problems that must be captured.

Consider first the feature [+Past], which is one of the options determining the relevant syntactic properties of tensed clauses, but also determines the various morphological realizations of past tense in English as discussed e.g. in Halle and Marantz (1993). Besides this function as a formal feature, past tense contributes to the conceptual interpretation by the condition (19)(b), where ' $e$ ' is a variable over states and events, to which I will return shortly, ' $u$ ' a variable for the (indexical) utterance event, and 'T $x$ ' a function assigning a time interval to ' $x$ ':

$$
\text { (a) } \quad[+ \text { Past }]
$$

\section{[ [ T e ] BEFORE [ T u ] ]}

Notice that the internal structure of (19b) is crucial for the interpretation at SF, while it must be 'invisible' to the syntactic and morphological effects of (19a) just mentioned. Hence the apparently simplest way to account for the non-arbitrary relation between (19)(a) and (b), viz. to replace [+Past] by its SF structure (19b), does not meet the actual requirement.

That this short cut is inappropriate becomes even more obvious if we consider the second example. In German (and various other languages) directional prepositions differ from their locative counterpart by the Case condition imposed on their complement: directional prepositions require Accusative, locative prepositions require Dative. Assuming a functor FIN that picks out the final part of its argument, ${ }^{21)}$ the contrast between locative and directional in (in/into) can be represented by (20a) vs. (20b):
(20) (a)
(a) / in /
[-V, -N, -Dir ]<smiles>[Y][R8]</smiles>
[ y [ LOC [ INTERIOR $x$ ]]]
(b) / in /

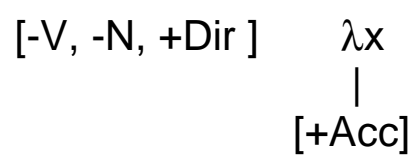
$\lambda y$
FIN y [ LOC [ INTERIOR $x$ ] ] ]

The point to be noted is that even though the locative/directional alternation is a lexical property of the individual prepositions including an (at), auf (on), vor (before, in front of), hinter (behind), über (above), unter (below), but not nach (to), aus (out of), there is an obvious systematicity relating Case assignment and directionality. This can be made explicit if we collapse (20)(a) and (b) by means of notational 
conventions proposed by Chomsky and Halle (1968) for rules of phonology into a complex entry like (21), where [+Oblique] distinguishes Dative from Accusative:

$$
\begin{aligned}
& / \text { in } / \quad[-\mathrm{V},-\mathrm{N}, \alpha \text { Dir }] \quad \lambda x \quad \lambda y \quad[(\alpha \text { FIN }) \text { y }[\text { LOC [ INTERIOR } x \text { ] ] ] } \\
& \text { [- }-\alpha \mathrm{Obl}]
\end{aligned}
$$

The variable $\alpha$ ranges over + and - , and the notation $\left({ }_{\alpha} X\right)$ indicates that $X$ is present if $\alpha$ is + , and absent otherwise. With these conventions, (21) states that the complement of the directional preposition must be [-Obl] - i.e. Accusative - and the component FIN in SF is present, while for the non-directional preposition the complement is [+Obl] - i.e. Dative - and FIN is absent from SF. Even though there is no direct interpretation of $[-\mathrm{Obl}]$ in terms of FIN, the relation is not a mere accident either: the Case feature realized by the object of the preposition is related to the presence or absence of FIN in SF by the value of the variable $\alpha$, which furthermore connects it to the feature [Dir] in the categorization. ${ }^{22)}$

Although (21) explicitly expresses the connection between subcategorization and semantic directionality, it still does not appropriately capture the relevant systematicity. As Chris Wilder (personal communication) observes, the analysis given in (21) does not exclude prepositions where the converse relation holds between subcategorization and directionality by simply registering the specification $[\alpha \mathrm{Obl}]$ instead of $[-\alpha \mathrm{Obl}]$. Hence an appropriate account should prevent arbitrary lexical Case by systematically connecting FIN to Accusative. This can be done in the following way:
(a) / in /
$[-\mathrm{V},-\mathrm{N}]$
$\lambda x$
$\lambda y$
$[($ FIN) y [ LOC
INTERIOR $\times$ ] ] ]
(b) For $[-\mathrm{V},-\mathrm{N}]$, the lowest position $\lambda \mathrm{x}$ is associated with [-Obl], if FIN $\mathrm{y}$ is present in its SF.

(22a) is the lexical entry for in, providing its locative or directional reading, depending on the absence or presence of the optional functor FIN, with the categorization [ + Dir] determined by general condition as mentioned in footnote 22 . The relation of directionality to Case is now represented by the general condition (22b), which can be construed as a lexical rule that belongs to the language particular conditions on Case-assignment to be discussed in section 4. It rests on two assumptions: First, the neutral Case, structurally assigned to the object position of prepositions is Dative (see (57c) below), such that locative prepositions, for which FIN is dropped, are automatically provided with [+Obl] for $\lambda x$. Second, lexically fixed, inherent Case features have precedence over those assigned by general conditions, including (22b), such that e.g. $z u$ (to) and nach (towards) will be blocked for (22b) by lexical [+Obl], even though both are directional. It might be noted that the choice of Dative as the structural Case of prepositions in German is an empirical issue, which might turn out to be wrong. This does not affect, however, the general orientation underlying (22), to which some comments are to be added.

First, the precise formulation of (22b) might be in need of modification, identifying the relevant components FIN and $\lambda x$ in more systematic ways by means of their structural position in AS and SF of the entry. Although matters of formulation are no 
marginal issue, they do not affect the main point to be made here. Second, the generalization about prepositions ranging from an (at) to zwischen (between) and exhibiting the pattern illustrated in (21) is now extracted and made explicit by (22b) (and condition (i) in note 22, for that matter). With this condition, arbitrary lexical alternatives of the sort mentioned above are excluded. Third, as (22b) explicitly shows, there is no intrinsic connection between Case features, which are assigned to $\lambda \mathrm{x}$, and the directionality component, which is a functor applying to $\mathrm{y}$. In other words, the argument marked by the relevant Case features is not responsible for the conceptual aspect of directionality. Fourth, even though (22b) extracts the generalization just discussed, it does not explain why directionality is related to Accusative rather than Dative, as pointed out by Jane Grimshaw (personal communication) - if there is anything to be explained.

Whether the SF-interpretation of formal features is in fact the same phenomenon in cases like (19) and (22) is by no means obvious (see also note 22). What they do have in common, though, is the fact that the relation between a formal feature and a semantic condition is not merely incidental or idiosyncratic.

Let me summarize the organization of lexical information as discussed so far: Besides $P F_{L E}$ and SF $F_{L E}$, the interfaces with extralinguistic systems, there are three types of information contained in the component GF $_{\mathrm{LE}}$ without direct external interpretation. First categorization in terms of formal features, second s-selection in terms of Argument Positions based on variables in SF LE$_{\text {, }}$ and third c-selection in terms of formal features associated with the Argument Positions.

The Argument Structure (or subcategorization component), comprising s-selection and c-selection, specifies crucial aspects of the combinatorial properties by which lexical items build up complex expressions. It also constitutes, in a way, the interface between syntax and semantics: on the one hand, Argument Positions project semantic variables into the range of possible syntactic arguments, on the other hand AS combines this semantically based information with the formal features determining its syntactic realization. Further aspects of this syntax-semantics interface, including those bearing directly on economy of lexical information, will be discussed below.

\section{Aspects of Parsimony in Lexical Representation}

There are a number of problems, not addressed in the examples discussed so far, that are relevant from a minimalist point of view. First, the discussion of shelve, based on the analysis of Hale and Keyser (1993), assumed the SF of put and on to be based on simple constants PUT and ON, which is certainly inadequate for principled reasons, if underspecification of lexical information is supposed to apply to SF $F_{L E}$. The entry for German in given in (22) illustrates the way in which further analysis of SF $F_{L E}$ might proceed, pursuing principles of componential analysis explored e.g. in Jackendoff (1990) and related work. The basic orientation of this analysis is close to that of underspecification in phonology. Instead of sketching a necessarily incomplete theory of underspecification in semantics, I will merely illustrate the issue by some examples. Consider verbs like open, clear, flatten, etc. related to the corresponding adjectives and appearing in either transitive (causative) 
or intransitive (unaccusative) constructions. In order to account for their lexical representation, I will introduce the following SF-components:

(23) (a) $x$ DO $P$ where $x$ represents an individual involved in the activity $P$

(b) e CAUSE e' where e represents an event that causes the event e'

(c) e INST $p$ where e instantiates the proposition $p$, a proposition being a set of eventualities.

As I am not striving for a model theoretic semantics, I will restrict myself to the intuitive interpretation of DO, CAUSE, and INST indicated in (23). ${ }^{23)}$ By means of these elements the following elements can be defined:

(24) (a) $x$ DO-CAUSE $p==$ DEF e INST [ $x$ DO $P$ ] \& e' INST $p$ \& e CAUSE e' (b) e INST [ BECOME $p$ ] ==DEF [ INIT e ] INST NOT $p$ : [FIN e] INST $p$

(24b) defines the change from not-p to $p$ by means of the functor FIN already mentioned and its counterpart INIT, which picks out the initial part of its argument. The colon ' $:$ ' in (24b) is to be interpreted as an asymmetrical conjunction, such that in $p: q$ the precondition $p$ must hold for the condition $q$ to be true or false. In other terms, $p$ is a presupposition of $q{ }^{24)}$ Hence the two states involved in BECOME $p$, viz. the source state NOT $p$ and the target state $p$, are asymmetrical in the sense that $p$ may be true or false only if it is preceded by NOT $p$. With these prerequisites, the lexical entries for intransitive and transitive open can be given as (26) and (27), respectively, assuming (25) for the adjective involved:

(25) $/$ open / $[+\mathrm{V},+\mathrm{N}] \quad \lambda \mathrm{x} \quad[$ OPEN $\mathrm{x}]$

(26) $/$ open $/[+\mathrm{V},-\mathrm{N}] \quad \lambda x \lambda \mathrm{e}[\mathrm{e}$ INST [ BECOME [OPEN x ] ] ]

(27) / open / [+V,-N ] $\lambda x \quad \lambda y \quad \lambda e$ [ e INST [ y DO-CAUSE [BECOME [OPEN x ] ] ] ]

Notice that for the two verbs open, the Argument Structure provides the eventposition $\lambda$ e based on the argument e of the operator INST in SFLE. This accounts for the reference of verbal constructions to states or events assumed by Higginbotham (1985) and others. This extension of AS together with its background in SF is, of course, to be assumed for shelve in (18) and for verbs in general. Morpho-syntactic aspects of this extension will be taken up directly, together with further issues, including the predictability of c-selection features. First, though, two general issues concerning SF need to be addressed.

On the one hand, the semantic interpretation of constructions containing the verb open must account for the two states involved in the transition from being closed to being open, and in particular for the presuppositional status of the source state, as shown by simple cases like (28), which are taken care of by the definition in (24):

(28) (a) He opened the box, because it was closed.

(b) \#He opened the box, because it was not closed in the first place.

(c) He did not open the box, because it was not closed in the first place

(d) He did not open the box, hence it remained closed as before. 
Considerations of parsimony and underspecification, on the other hand, require $\mathrm{SF}_{\mathrm{LE}}$ to be free of predictable information. We thus have to motivate entries like (26) and (27) in two directions: that they need to specify the degree of decomposition assumed here, and that they need and must not specify more. Let me take up the second point first.

The fact that causation involves two events, instantiating the cause and the effect, respectively, and that the change of state indicated by BECOME requires a precondition and a condition (or source- and target-state, for that matter) is clearly relevant for the interpretation in $\mathrm{C}-\mathrm{I}$, and it has usually been taken for granted, e.g. in most of the literature on presupposition, that these conditions belong to the structure of I-Language. ${ }^{25)}$ If this assumption is correct, the interface that relates I-Language to $\mathrm{C}$-I must explicitly contain the conditions specified in the definiens for DO-CAUSE, BECOME, etc. instead of the definitionally reduced representations. In other words, the SFLE of (26) must be expanded into (29):

$$
\text { [ [ INIT e ] INST NOT [ OPEN x ] : [ FIN e ] INST [ OPEN x ]] }
$$

Similarly for (27). If the reduction of (29) to (26) on the basis of (24b) is not merely a notational issue, but does relate to empirical matters, as I will argue below, then (26) is somehow the semantic counterpart to phonological underspecification. ${ }^{26)}$ In other words, even if structures like those in (26) and (29) do not constitute separate levels of representation, but merely different degrees of specification with respect to one level, they must still be considered as distinct aspects of the overall representational system of Semantic Form.

Consider now reasons why the compositional structure of $\mathrm{SF}_{\mathrm{LE}}$ for open should at least be as detailed as in (26)/(27). The difference between the causative and the inchoative (i.e. unaccusative) version of open does not only turn on the Argument Position of the Agent, but also on the Causative component that is present in (30)(a) and the passive (b), but not the inchoative (c):
(30) (a) He opened the door
(b) The door was opened
(c) The door opened

In a similar vein, the presence of BECOME in both (26) and (27) as opposed to (25) is born out by the contrast between $(31)(a)$ and (b), where (b) needs the copula be to provide the event-instantiation and Tense.
(31) (a) The shop opened in the morning
(b) The shop was open in the morning

The systematicity underlying these examples is borne out not only by verbs like open, clear, darken, fasten, stiffen, etc. whose resulting state is described by a pertinent adjective, but by the large class of verbs like break, change, turn, etc. often called 'ergative'. Notice, however, that in spite of this systematicity, the two verbs open cannot simply be dismissed in favor of prelexical syntax incorporating the relevant adjective. The existence of the verbs and the adjectives and their specific $\mathrm{PF}_{\mathrm{LE}}$ must rather be registered as a lexical fact. Thus, while the adjective clear provides both the causative and the inchoative verb, clean provides only the causative option. 
The notational conventions applied earlier to the locative and directional prepositions allow for a simplification in the case of causative/inchoative verbs in the same vein. Consider two of the various readings of get occurring in (32)(a) and (b) with the entries in (33) and (34), respectively, where $\mathrm{P}$ is a variable over prepositional phrases and other predicates:

(32)(a) He got them into the room

(b) They got into the room

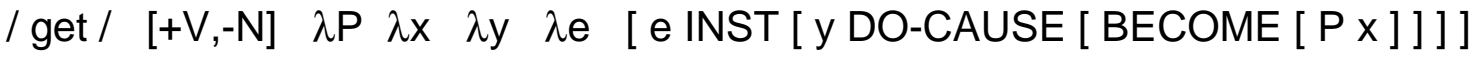

$$
\begin{aligned}
& / \text { get } /[+\mathrm{V},-\mathrm{N}] \quad \lambda \mathrm{P} \lambda \mathrm{x} \quad \lambda \mathrm{e}[\mathrm{e} \text { INST [ BECOME }[\mathrm{P} x]]]
\end{aligned}
$$

The way in which (33) and (34) can be collapsed is indicated in (35), where $\lambda y$ is present in AS iff the Cause-component is present in SF:

$$
/ g e t /[+\mathrm{V},-\mathrm{N}] \lambda \mathrm{P} \lambda \mathrm{x}\left({ }_{\alpha} \lambda \mathrm{y}\right) \lambda \mathrm{e}\left[\mathrm { e } \text { INST } \left[\left({ }_{\alpha} \mathrm{y}\right.\right.\right. \text { DO-CAUSE) [ BECOME [P x ] ] ] ] }
$$

There is some evidence that the notational conventions borrowed from phonology do in fact express empirically relevant generalizations. Assuming the predictability of features specifying c-selection in ways to which we will return, $\lambda x$ in (35) is associated with Accusative, iff $\lambda y$ is present, receiving Nominative otherwise. But this is exactly what has been called Burzio's Generalization, which now follows from more general conditions on lexical items. To be more precise, the effect of Burcio's Generalization depends on the interaction of conditions on structural Case like those in (57) below, and the principles of disjunctive ordering as used in (35), the latter providing the alternative structures to which the former apply. It should be obvious, that (26) and (27) collapse in the same way. We might consider, however, a further step including the adjective (25) into one entry in the following way:

$$
\begin{aligned}
& \text { / open / }[+\mathrm{V},-\beta \mathrm{N}] \\
& \left.\left.\lambda \mathrm{x}\left(\beta\left({ }_{\alpha} \lambda \mathrm{y}\right) \lambda \mathrm{e} \quad[\mathrm{e} \text { INST [ ( } \alpha \text { y DO-CAUSE) [ BECOME) [OPEN } \mathrm{x}]\right]\right]\right]
\end{aligned}
$$

Besides the optional DO-CAUSE component and the Agent Position bound to it, (36) relates the value of the categorial feature $\mathrm{N}$ to $\mathrm{AS}$ and SF in such a way, that only the information of $(25)$ is left, if $[+\mathrm{N}]$ is chosen in the categorization component. Two points are worth noticing in this respect. First, this reduction would be extremely complex - if possible at all - on the basis of the 'expanded' representation derived by means of (24), indicating the pre-state and the target-state separately. Second, the independently motivated notational conventions for disjunctive ordering of phonological rules naturally apply to lexical information of various sorts. This does not show, of course, that the analysis under consideration is correct, but it might suggest that it is on the right track. Notice, incidentally, that the idiosyncrasy blocking e.g. the inchoative reading for clean would come out as (37), where, differing from (36), there is no optionality of the DO-CAUSE component in the case of $[+\mathrm{V},-\mathrm{N}]$, i.e. if $\beta$ is $+{ }^{27)}$

\section{(37) / clean / $[+\mathrm{V},-\beta \mathrm{N}]$}

$$
\lambda x \quad(\beta \text { y } \quad \lambda e \text { [e INST [y DO-CAUSE [BECOME ) [ CLEAN x ]]]] }
$$


So far, considerations of economy in lexical information concentrated on $\mathrm{SF}_{\mathrm{LE}}$, touching only occasionally on categorization and subcategorization, to which I will turn now more systematically.

A rather general point to be noted here concerns the fact that Argument Structure depends on both syntactic and semantic conditions in rather specific ways. One aspect of this dependency relates to the ranking and content of Argument Positions discussed earlier. Due to (16), conditions of $S_{\mathrm{LE}}$ are projected into AS, thereby ultimately determining the syntactic behavior of lexical items. I will consider now conditions relating AS to syntactic category features. To this effect, the following types of Argument Positions will be distinguished:

(38) (a) Referential vs. nonreferential Positions

(b) Designated vs. nondesignated Positions

(c) Obligatory vs. optional Positions

A Referential Position can be used to specify a referential domain with respect to which the type of reference is determined by an appropriate functional category. ${ }^{28)}$ The functional elements to be considered here are $D$ for nouns and $C$ (and possibly Tense) for verbs. The notion of a Designated Role modifies or generalizes the earlier distinction between external and internal Positions, which became inadequate under the VP-internal subject analysis. Roughly speaking, the Designated Argument Position of a lexical item is that of a possible subject. As we will see shortly, this holds for all major lexical categories. The distinction of optional vs. obligatory arguments should be obvious. It lies behind contrasts such as (39)(a) and (b), turning on the pseudo-intransitive use of verbs like read, drink, etc. which is not available for donate, demote, etc.

(39) (a) He didn't want to read (it)

(b) He didn't want to donate *(it)

With these distinctions in mind, the following generalizations can be formulated. Let (40) be the schema of the Categorization and the Argument Positions of any lexical entry LE; then the conditions (41)(a) - (e) hold:

$$
[\alpha \mathrm{V}, \beta N, \ldots] \quad \lambda x_{n} \ldots \lambda x_{1} \lambda x_{0} \quad \text { for } n \geq 0
$$

(41) (a) For any LE, there is exactly one Designated Position $\lambda x_{i}$.

(b) $\lambda x_{i}$ is nondesignated iff $\lambda x_{k}$ is the Designated Position and i $>k$.

(c) For $[+\mathrm{N}]$, any non-designated Position $\lambda x_{k}$ is optional.

(d) $\lambda x_{0}$ is a Referential Position iff $\alpha=-\beta$ for $[\alpha \mathrm{V}, \beta N]$.

(e) For [+V], the Designated Position is not a Referential Position.

According to (41a) any major lexical category, including N, A, and P, has a potential subject position. Its actual realization by a syntactic subject might involve a copula, however, as illustrated in (42):
(42) (a) He is happy.
(b) She was in London.
(c) He became a doctor. 
(41b) requires the Designated Position to rank above all non-designated ones, which are, moreover, always optional for Adjectives and Nouns according to (41c). This means, that $[+\mathrm{N}]$-items have only weak capacity to govern complements. ${ }^{29)}$ In other words, for Adjectives and Nouns, optionality of complements is the default case, while Verbs and Prepositions require their complements to be syntactically realized, unless they are lexically marked as optional (as illustrated in (39)). According to (41d), all and only Nouns or Verbs are capable to establish referential domains by means of their highest Argument Position. For Nouns, this capacity is based on the Designated Position because of (41b), while (41e) requires the Referential Position of Verbs to be different from and hence higher than the Designated Position. Thus the event reference of Verbs is a consequence of (41e), if the highest position of Verbs is automatically related to the event instantiation in SF. ${ }^{30)}$ Condition (41e) is stated for [+V]-elements, but it doesn't have any effect for Adjectives, as these, according to (41d), don't have a Referential Position in the first place. It might be noted, incidentally, that it is only for Verbs that the Event Position must be different from the Designated Position, while for event nominals like fall, kick, destruction, etc. the event instantiation provides the Referential as well as the Designated Position, as can be seen in (43)(a) and (b), respectively:

(43) (a) John's arrival came as a surprise.

(b) The first scene is the arrival.

As a matter of fact, most of the differences between arrive and arrival follow from the conditions in (41), if the affix -al simply changes the categorization from Verb to Noun. ${ }^{31)}$

Notice that (41e) implies a subject position for verbs, even if there is no semantic variable to be bound by it, as e.g. in the so-called weather verbs. Hence in order to

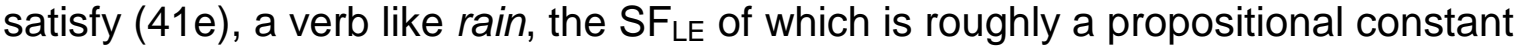
RAIN instantiated by an event, must provide an improper argument $\lambda x$, which is an empty operator to be saturated by a semantically empty subject. On the basis of these considerations the entry for rain could be (44), which accounts for both the Noun and the Verb:

$$
\text { / rain / } \quad[\alpha \mathrm{V},-\alpha \mathrm{N}] \quad(\alpha \lambda x) \lambda \mathrm{e} \quad[\mathrm{e} \text { INST [ RAIN ] ] }
$$

For $+\mathrm{V}$, the subject position is present, for $+\mathrm{N}$ it is missing. Under this interpretation, (41) characterizes wellformed Argument Structures. But one might interpret (41) just as well as principles simplifiying lexical information, such that (44) reduces to (45), the Argument Positions following from (41):

$$
\text { / rain / } \quad[\alpha \mathrm{V},-\alpha \mathrm{N}] \quad \text { [ e INST [ RAIN ] ] }
$$

The conditions given in (41) can be expressed in various ways; they may, in particular, be stated in terms of features that differ from $\mathrm{V}$ and $\mathrm{N}$ in certain respects, a problem that I will not take up here ${ }^{32)}$. The notions made explicit in (41) could intuitively be paraphrased as follows:

(46) (a) V and $\mathrm{N}$ are primary categories, due to their referential capacity.

(b) Verbal reference is separate from grammatical subject position.

(c) N and A are 'weak' governors. 
I will leave it open to what extent these conditions are parameterized, i.e. susceptible to language particular variation. ${ }^{33)}$ What I want to emphasize, though, is the fact that (41) indicates the type of interpretation associated with the formal features for syntactic categorization: syntactic features, differing in this respect from morphological features discussed above, are related to computational properties exclusively, based on categorization, subcategorization, and their combinatorial consequences.

These properties include also the morphological features associated with the Argument Positions according to conditions to which I will turn next. It should be obvious that these conditions must be sensitive to language particular variation, depending on the morphological categories realized in a given language. Instead of going into the necessarily varied details, I will merely indicate the lines along which cselection features can be associated with positions indicating s-selection.

The first point to be noted is the well known distinction between structural, i.e. predictable, and lexical, i.e. idiosyncratic, features. Although this distinction has largely been applied to Case, it is equally relevant for categories like Status in the sense of Bech (1955). Let me begin by briefly illustrating the character of idiosyncratic c-selection, as this clearly shows where the pertinent features must be assigned. In the following German examples, (a) is the canonical type with respect to which (b) exhibits inherent lexical information, marked by italics:
(a) Wir schliefen (We slept)
(b) Wir froren / Uns fror
(We felt cold)
(He met her)
(b) Er begegnete ihr (/*sie)
(He met her)

(48) (a) Er traf sie

(49) (a) Er sagte ihr etwas

(b) Er fragte sie (/*ihr) etwas

(He told her something) (He asked her something)

(50) (a) Er glaubte, daß er stieg/ Er glaubte zu steigen

(b) Er begann zu steigen $\left(/{ }^{*} \mathrm{daß}\right.$ er stieg)

(He thought he was rising)

(He began to rise)

(51) (a) Er behauptet, daß er krank ist/ krank zu sein

(He claims to be ill)

(b) Er sagt, daß er krank ist (/*krank zu sein)

(He says that he is ill)

(47) to (49) have to do with lexical Case, (50) and (51) illustrate conditions on finite and infinite complement clauses. More specifically, frieren in (47b) belongs to a small group of verbs whose designated argument can be realized by the regular Nominative wir or the idiosyncratic Accusative uns. In (48), begegnen illustrates the somewhat larger group of verbs whose only object must idiosyncratically be realized by a Dative like ihr instead of the canonical Accusative sie. The idiosyncrasy of fragen in (49b) on the other hand lies in the fact that the indirect object must be realized as the Accusative sie instead of the regular Dative ihr. The way in which these conditions may enter the lexical information has provisionally been indicated in (18) and (20) - (22). Thus the lexical Case of verbs like frieren or fragen yields entries like (52) and (53):

$$
\text { / frier / } \quad[+\mathrm{V},-\mathrm{N}] \quad \lambda \mathrm{x} \quad \lambda \mathrm{e} \quad[\mathrm{e} \text { INST [ COLD } \mathrm{x}]]
$$


$([+\mathrm{Obj}])$

(53) / frag / $\quad[+\mathrm{V},-\mathrm{N}]$

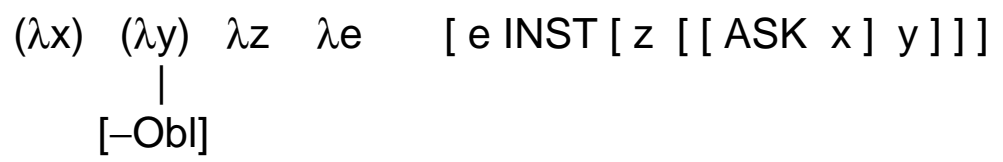

The feature [+Obj] distinguishes Accusative and Dative from Nominative, [+Obl] distinguishes Dative from Accusative, as noted earlier. More generally, we might tentatively characterize the morphological Cases of German as follows:

$$
\text { Nominative Accusative Dative Genitive }
$$

$\begin{array}{lllll}\text { Objective } & - & + & + & - \\ \text { Oblique } & - & - & + & +\end{array}$

With these notational conventions, (52) indicates that the subject of frieren may optionally be realized as Accusative ${ }^{34)}$, while (53) requires the indirect object to be non-oblique, i.e. Accusative, instead of the Dative normally assigned to the indirect object. ${ }^{35)}$ Notice, incidentally, that the parentheses in (53) indicate the optionality of the direct as well as the indirect object, attested by sentences like (55), all of which are grammatical:
(55) (a) Er hat dich etwas gefragt
(c) Er hat etwas gefragt
(b) Er hat dich gefragt
(d) Er hat gefragt

In a similar vein conditions determining finite and infinite complement clauses, including Exceptional Case Marking, and a number of related phenomena must be accounted for. I will not go into the complex issues that a reasonable account would have to deal with.

Although idiosyncratic c-selection as illustrated so far must simply be lexically registered, its specification depends on structural conditions in two respects. First, underspecified, redundancy-free characterization of lexical Case requires general conditions that account for the canonical information to be filled in. Thus the canonical Accusative of the direct object in (53), as well as the feature [+Obj] to complete the idiosyncratic Accusative, must follow from general conditions. Second, even the idiosyncrasy of lexical Case is subject to limiting constraints. For example, while German has a small set of verbs governing two Accusatives, there are no verbs requiring two Datives. In a way, the conditions to be considered in this respect set the stage for both structural and idiosyncratic c-selection.

The first of these conditions seems to be independent of any language specific morphology:

(56) The highest Argument Position $\lambda x_{0}$ in (40) is never associated with c-selection features.

Together with the conditions of (41), principle (56) has a number of interesting consequences. First, it prevents the Designated Argument of all categories except $V$ from carrying any morphological information. This accounts for the fact that N, A, and $\mathrm{P}$ as (heads of) predicatives do not specify the necessary Case information to 
identify the subject, but rather depend on the copula (and its INFL) to this effect. Second, it allows $A$ and $P$ to act as (heads of) modifiers, which can unify their Designated Argument Position with an Argument of the modified head, a possibility to which I will return shortly. Third, it provides the basis for referential interpretation of $\mathrm{N}$ and $\mathrm{V}$ by means of their respective functional heads $\mathrm{D}$ and $\mathrm{C}{ }^{36)}$

In a way, (56) tells morphological information where not to go. As it does not refer to any specific features, it should be construed as a principle of UG, not restricted by language particular properties. The following conditions, on the other hand, indicate how morphological information is actually distributed. As should be expected, this distribution depends, among other things, on syntactic categorization, and it must be susceptible to language particular conditions to the extent to which morphological Case features are subject to language particular variation. (57) determines Structural Case for German (the parentheses in (57a) indicating the options of intransitive, transitive, and ditransitive verbs):

(57) (a) Structural Case for entries of category $[+\mathrm{V},-\mathrm{N}]$ :

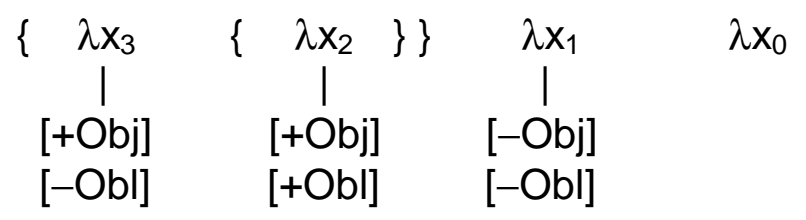

(b) Structural Case for entries of category $[+\mathrm{N},-\mathrm{V}]$ :

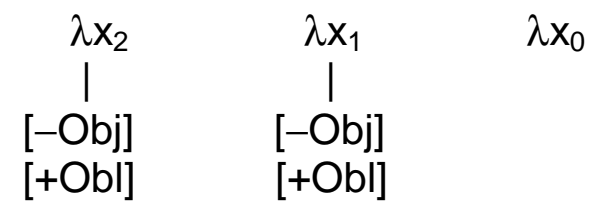

(c) Structural Case for entries of category $[\alpha \mathrm{N}, \alpha \mathrm{V}]$ :<smiles>[Y10][OH+][TeH]</smiles>

According to (57a), Dative can occur only if Accusative can be assigned, and Accusative presupposes that Nominative is assigned (the latter usually called Burzio's Generalization, as already mentioned). For nouns, complements are optional anyway, hence no interdependency is indicated - although this is not the whole story. (57c) applies to adjectives and prepositions, expressing the somewhat provisional generalization that Structural Case of the sole possible object is Dative in both cases. This assumption is based on the observation that adjectives allowing objects, like bequem (convenient), ähnlich (similar), or bekannt (known), and prepositions not participating in the locative/directional alternation shown in (22), i.e. prepositions like mit (with), bei (near), von (from/of), or nahe (near) take Dative complements, irrespective of the thematic role assigned. It might be noted that by virtue of (56) $\lambda x_{0}$ is never associated with Case features and could hence be dropped from (57), such that only positions actually taking Structural Case are referred to. Notice furthermore that assignment of Nominative in accordance with 
(57a) might be dependent on Tense or Finiteness, a point that will be left aside here. The general consequence to be emphasized, however, is the simplification of lexical entries, from which all features predicted by (57) are to be eliminated.

Let me conclude this discussion of c-selection with the following remarks. First, as already noted, Structural Case assignment is language particular - thus (57) turns on German Case features as sketched in (54), and it is category specific, verbs differing also in this respect from nouns, adjectives, and prepositions. It remains to be seen whether and how Structural Case conditions can be reduced to universal principles from which (57) would emerge by appropriate choice of parameter values. ${ }^{37)}$ Second, (57) states only conditions on nominal complements, which realize Case. It has to be extended in non-trivial ways to conditions on Argument Positions assigned to CPs, PPs or APs, instead of DPs. These extensions must furthermore take care of Argument Positions for which no structural features are available, such as prepositional objects. Even though these extensions will involve issues left aside here - e.g. the conditions to which the choice between finite and infinite complement clauses is related - (57) illustrates central mechanisms of c-selection and the economy of lexical information which they provide for. Finally, as already mentioned, structural conditions like (57) provide the background against which lexical features of c-selection operate, overriding, so to speak, the default conditions of Structural Case. ${ }^{38)}$

I need not emphasize that the organization of lexical information as discussed so far is crucially related to its role in combinatorial processes yielding syntactically mediated PF-and SF-representations. Even though a detailed account of these problems clearly would go beyond the present limits, some of the broader perspectives will be sketched in the next section.

\section{Combinatorial Aspects of Lexical Entries}

A crucial idea of the Minimalist Program is to dispense with language particular syntactic rules, and even general combinatorial schemata, like X-bar syntax, deriving the complex, combinatorial structure by means of simple, elementary operations with all specific effects due to lexical information. The elementary operations are 'Merge' and 'Move', where Merge applies to two units taken either from the lexical system or constructed by means of Merge and Move. Move picks up a component characterized by a formal feature within a given structure built up by Merge and Move and assigns it to a specific place according to highly restricted possibilities. Of these two operations, Merge is obviously foundational, Move adjusting, so to speak, the results of the merger of lexical information into larger units. The following remarks will largely be restricted to comments on the way in which Merge depends on lexical information and the effects it creates. ${ }^{39)}$

The assumption about Merge in the Minimalist Program is that it combines two componnents $X$ and $Y$ into a complex unit with one of the merging components being its head. The characteristic properties of the head become the characteristic properties of the whole. Starting with lexical items, the characteristic properties of $X$ have usually been taken to be the categorization of $X{ }^{40)}$ Thus the general schema determined by Merge is (58), where $X^{\prime}$ is a copy of the categorization of $X$ : 
(b)

One of the issues to be settled is the choice between (58)(a) and (b), i.e. the question how linear ordering of $X$ and $Y$ is determined. According to considerations expressed in (4) above, linear ordering is irrelevant for SF (or LF, for that matter), and I will assume for matters of exposition that it is determined by some linearization principle for $\mathrm{PF}$, where linearization is likely to be parameterized and dependent on information in X'. This is not a principled choice, and the following considerations do not depend on it. There is a consequence to be drawn, however, with respect to the status of $X^{\prime}$, i.e. the categorization of $X$, for lexical items that are syntactically complex. Instead of going into the complex problems related to idioms like take advantage of in this and various other respects, I will briefly illustrate the issue for German prefix verbs like aufhören or anfangen, which are core items for a number of reasons. They are fixed units, many of them with a non-compositional, lexicalized Semantic Form, on which Argument Positions depend in the usual way. But while they are lexical units in these respects, they are syntactically complex, with movement separating the inflected stems from the prefix as shown in (59b):

(59)(a) Da er wenig später aufwachte

(b) Er wachte wenig später auf

(As he woke up a little later)

(He woke up a little later)

However Verb-second phenomena of German and related languages are analyzed see Wilder (1995) for a recent approach - the alternation shown in (59) clearly requires the inflected stem wachte, rather than the lexical compound aufwachte, to be the relevant syntactic unit with regard to verb placement. As a natural conclusion of this observation, the projection of features assumed in (58) generalizes to the internal structure of lexical entries. In other words, categorization not only applies to a lexical item as a whole, but also to its syntactically relevant parts. We thus get lexical entries as illustrated in (60):

(60)(a) $\quad[[+\mathrm{V},-\mathrm{N}][[-\mathrm{V},-\mathrm{N}] /$ auf/ $][[+\mathrm{V},-\mathrm{N}] /$ wach/ $]]$

(b) $\lambda x \quad \lambda e \quad$ [e INST [ BECOME [ NOT [ ASLEEP x ] ] ] ]

The more familiar notation of (60a), which integrates PF with categorization, is given in (61), assuming that the prefix auf is to be categorized as a preposition:

$\mathrm{V}$

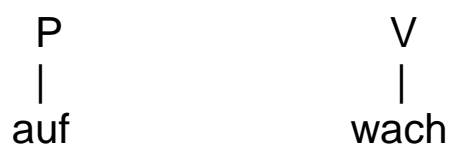

Notice that these considerations lead to a bipartition of lexical information: one part consists of PF with categorization imposed on it, the other part consists of SF with subcategorization attached to it. Although this bipartition does by no means reduce the importance of conditions interrelating categorization and subcategorization, as discussed above, it suggests a slightly different distinction of lexemes and lemmas mentioned earlier: Now a lexeme is not just the PF of a lexical item, but rather a categorized PF, such that e.g. open in (35) counts as two lexemes, viz. a verb and 
an adjective, while the transitive and the intransitive verb are two lemmas, related to one lexeme. There seems to be a number of facts which turn this bipartition into a substantial assumption that goes beyond a mere terminological convention. Among these facts is the relative autonomy of morphological processes that apply to a stem irrespective of the integrated lexical units in which it participates: give is subject to the same inflectional pattern gave, given in forgive, give up, give in, etc. each of which related to a different lemma. Similar phenomena of strong or irregular as opposed to weak or regular inflection show up in German, (62) giving a incomplete illustration:

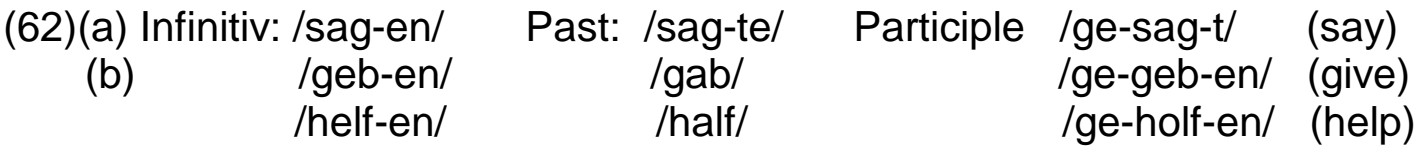

While regular inflection, adding e.g. the past tense affix /-te/ in German or /-d/ in English, can be expressed by a fairly general operation, the formation of past tense or past participle in cases like (62b) requires lexical specification of the relevant properties of PF related to the categorization in question. This relation between PF and categorization carries over to complex items based on the simple stem:

$\begin{array}{ll}\text { /ver-geb-en/ } & \text { /ver-gab/ } \\ \text { /er-geb-en/ } & \text { /er-gab/ } \\ \text { lauf-geb-en/ } & \text { /auf-gab/ } \\ \text { /ein-geb-en/ } & \text { lein-gab/ } \\ \text { /nach-geb-en/ } & \text { /nach-gab/ }\end{array}$

/ver-geb-en/

ler-geb-en/

(forgive)

lauf-ge-geb-en/

(result in)

(give up)

lein-ge-geb-en/

(put in)

/nach-ge-geb-en/ (give way)

Wunderlich (1992, this volume) shows that a parsimonious characterisation of morphological properties illustrated in (62b) and (63) can be given by means of patterns that relate differences in PF to minimal distinctions in the categorization of the stems involved. In other words, morphological categorization of inflected compounds like (63) depends on the categorization of the stems involved. The systematic relations among inflectional forms of basic items must therefore be available to the complex items they support. Hence (64a) must carry along its inflectional properties to (64b) and all other compounds based on geben:

(64) (a) $[[+\mathrm{V},-\mathrm{N},+\mathrm{Fin}] / \mathrm{gab} /]$

(b) $[[+\mathrm{V},-\mathrm{N},+$ Fin $][[-[\mathrm{V},-\mathrm{N}] /$ auf/ $][[+\mathrm{V},-\mathrm{N},+$ Fin $] / \mathrm{gab} /]]]$

In other words, (64a) must be available as a lexeme, irrespective of the SF and the subcategorization associated with it. It should be noted, by the way, that these are by no means side issues related to a few marginal entries; they must rather be recognized as typical phenomena of inflectional morphology, instantiating the socalled 'bracketing paradox' dealt with e.g. in Pesetsky (1985) and Bierwisch (1987).

Returning to problems of syntactic and semantic compositionality, we notice next the crucial role that subcategorization plays in determining the legitimate combination of two constituents $X$ and $Y$ : the Argument Structure of the head $X$ determines the nature of the complement $Y$ it combines with by the $s$ - and $c$-selection conditions represented by the Argument Positions of $X$. This type of combination has been sketched in section 3, it corresponds to what used to be called Theta-Marking under Case-Assignment, and it can be characterized as in (65): 
(65) Complementation: The head $X$ merges with the complement $Y$ into $\left[X^{\prime}[X \quad Y]\right.$ ] iff

(a) the categorization $Y^{\prime}$ of $Y$ is compatible with the c-selection conditions associated with the (lowest) Argument Position $\lambda \times$ of $X$;

(b) the Argument Position $\lambda x$ of $X$ is saturated by functional application.

The functional application referred to in (65b) is usually construed as lambda conversion, such that the operator $\lambda x$ is deleted and the variable bound by it is substituted by the SF of the complement - or rather by that SF with whatever is left of its Argument Structure. As a result of (65b), the Argument Structure of [ $X^{\prime}[X Y$ ] ] is that of its head $X$ minus the position $\lambda x$ just discharged. We might also say that the features associated with $\lambda x$ have been matched and disappear, whereas the categorization of $Y$, which they must match, remain part of the categorization of $Y$ in the resulting unit $\left[X^{\prime}[X Y]\right]$. Hence subcategorization information is saturated and eliminated by Complementation, while the categorization of the head as well as of the complement is preserved - alongside with PF and SF. (67) illustrates the effect of (65) by merging the copula be, provisionally given in (66), with the predicative adjective open represented in (25) above.

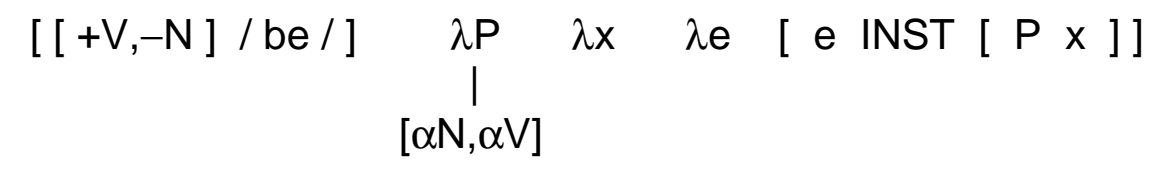

$$
\begin{aligned}
& \text { (67) }[[+\mathrm{V},-\mathrm{N}][[[+\mathrm{V},-\mathrm{N}] / \text { be / ] [ [+V,+N]/open / ] ] ] } \\
& \lambda x \quad \lambda e[\text { e INST [ } \lambda z[\text { OPEN z ] x ] ] } \\
& \text { (68) } \lambda x \quad \lambda e \quad[\text { e INST [OPEN x ] ] }
\end{aligned}
$$

The SF of (67) reduces to (68) by lambda conversion, eliminating the Designated Position of the adjective. It must be noted that although functional application is indeed what Complementation essentially boils down to, a proviso is to be made with respect to projections of the functional heads $C$ and $D$ to which I will return shortly.

In addition to the head-complement combination, there is the option to combine a head with an adjunct, which usually functions as a modifier of the head. As the levels of projection assumed in X-bar syntax are eliminated under minimalist assumptions, the effect of Merge for adjuncts and complements is essentially the same, viz. (58), except that a different type of categorization is stipulated for adjunct constructions. ${ }^{41)}$ Suppose now that we avoid such stipulation, relying on the fact that adjuncts do not saturate an Argument Position, such that Adjunction does not reduce the Argument Structure of the head, but rather that of the adjunct.

Assuming that the effect of adjoining e.g. the adjective open to the head door must be something like (69), we get (70) as the operation that merges an adjunct with its head.

(69) $[[+\mathrm{N},-\mathrm{V}][[[+\mathrm{N},+\mathrm{V}] /$ open / ] [ [+N,-V] / door / ] ] ]

\section{$\lambda x[[$ DOOR $x] \&[$ OPEN $x]]$}

(70) Adjunction: The head $\mathrm{X}$ merges with the adjunct $\mathrm{Y}$ into $[\mathrm{X}$ [ $\mathrm{X} Y \mathrm{Y}]$ ], iff 
(a) the Designated Argument Position $\lambda x$ of $Y$ can be unified with a position of $X$;

(b) the SF of $Y$ forms the logical product with that of $X$ wrt. the unified Argument Position.

(70) is a simplification in certain respects and hence in need of modification. First, it accounts only for extensional modification, as in open door, where the referent is both a door and open. Non-extensional cases like alleged thief must be treated separately, not only because here the referent is not both a thief and alleged, but also because alleged cannot occur as a predicative adjective syntactically. Second, (70a) does not specify the conditions that select the position of $X$ that $Y$ unifies with. (71) illustrates the possibility of alternative options

(71) He left her in a bad mood.

Finally, logical product formation assumed in (70b) is the minimal assumption about the connection of head and modifier, although a slightly more specific relation might be required, the head providing a precondition for the condition of the modifier, in the sense mentioned in note 24 . Whatever needs to be adjusted for an appropriate account of modification, it does not seem to affect the crucial condition that a head taking an adjunct preserves its Argument Structure, while a head taking a complement does not, as it must discharge a position to the complement in question. Schematically, the difference can be indicated as in (72), where the arrow indicates discharging of an Argument Position:

(72) (a) Complementation

$$
X^{\prime}
$$

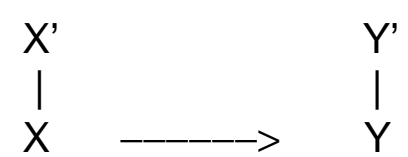

(b) Adjunction

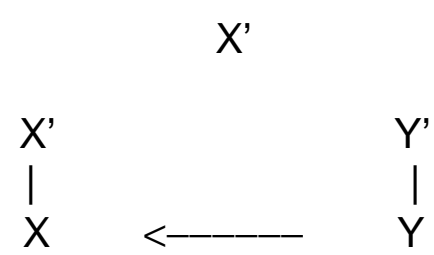

To conclude this rather provisional discussion of combinatorial effects related to Argument Positions, I will briefly comment on the saturation of the Referential Position considered as crucial for verbs and nouns. While Higginbotham assumes a third way to discharge an Argument Position, which he calls Binding of a Thematic Role, it seems natural to me to consider referential binding as an effect of the pertinent functional heads $D$ for nouns and $C$ for verbs. Thus the configuration [ F' [ $F$ $X]$ ], where $F$ is a functional head, takes $X$ as the complement of $F$, saturating at the same time the Referential Position of X. Suppose, as a first approximation, that (73) is the entry for the definite determiner:

$$
\begin{aligned}
& {[[+\mathrm{F},+\mathrm{N}] / \text { the } /]} \\
& \underset{+N,-V]}{\lambda Y}\left[\operatorname{DEF} x\left[\begin{array}{ll}
Y & x]
\end{array}\right]\right.
\end{aligned}
$$

The c-selection associated with $\lambda Y$ might in fact be automatically determined by the categorization of $\mathrm{D}=[+\mathrm{F},+\mathrm{N}]$, such that $\mathrm{D}$ takes nouns as complement. While this fits into the schema of complementation, two important problems to be solved should at least be mentioned. First, if $D$ relates to the referential domain defined by the nominall constituent it combines with, then the variable $x$ in (73) must be available for 
referential indexing. Second, the element that functional application of a lexical head to its complement applies to in case of DP complements must be exactly this referentially indexed variable, while the proper Semantic Form of the DP determines the domain from which the value of the variable is to be chosen according to the operation specified by D. Thus the VP open the door should come out as something like (74), where [DEF $x^{i}$ [ DOOR $x^{i}$ ] ] must be construed as a generalized quantifier in the sense of Barwise and Cooper (1981) and later discussion ${ }^{42)}$ :

$$
\text { [ V [ [ V/open/ ] [ D [ [ D/the/ ] [ N/door/ ] ] ] ] ] }
$$

$\lambda y \quad \lambda e\left[\right.$ [DEF $x^{i}\left[\right.$ DOOR $\left.\left.x^{i}\right]\right]$ : [ e INST [ y DO-CAUSE [BECOME [OPEN $\left.\left.\left.\left.\left.x^{i}\right]\right]\right]\right]\right]$

There are various problems to be clarified here that I will not provide with ad hoc solutions, as they obviously go beyond the organization of lexical information, although they clearly are not independent of it. One of the obvious consequences of these matters concerns lexical entries for DPs like he, she, who, etc., the treatment of which would require, however, a fair amount of further discussion relating to combinatorial syntax as well as semantics. Another set of problems would arise with any attempt to give an appropriate account of the properties and combinatorial consequences of complementizers, i.e. the elements binding the referential argument position of verbs. ${ }^{43)}$

\section{Conclusion}

In this paper, I have been concerned with the tension that holds between two equally cogent perspectives on the nature of lexical information. On the one hand, the lexicon is just a list of "exceptions“, i.e. the collection of anything that does not follow from general principles - either those of UG or those of a specific language. On the other hand, this idiosyncratic information must be represented in an „optimal coding“, i.e. according to conditions relating not only to intra-lexical economy, but also to external conditions and effects, both intra- and extra-linguistically. See Chomsky (1995) for a recent statement of this tension. In the final section of this paper, I will summarize the considerations and suggest a tentative conclusion concerning the nature of lexical information.

Lexical information consists of collections of basic elements of linguistic structure. For principled reasons, these elements fall into different categories - phonetic features, interpreted in A-P, semantic primes, interpreted in C-I, and formal features, determining language-internal properties with only partial and indirect interpretation in extra-linguistic domains. The structure and interpretation of these repertoires is determined by UG, with language particular systems selected from the general inventory and possibly parameter values fixed by language specific options. This universal background of the basic inventory constitutes a first aspect of systematicity underlying the idiosyncratic lexical infomation. In other words, what might enter the list of lexical items comes from a highly organized domain of possibilities, determining to a large extent the „optimal coding“. An equally important aspect concerns the configuration of the primitive elements within the individual lexical items. This aspect has at least two facets. First, there are the systematic components of a lexical entry, viz. $P F_{\mathrm{LE}}, \mathrm{SF}_{\mathrm{LE}}$, and $\mathrm{GF}_{\mathrm{LE}}$, the latter consisting of categorization and subcategorization, which in turn comprises s- and c-selection. 
These components are related to the levels of I-Language, although for fundamental reasons, they cannot simply be reduced to these levels, since $\mathrm{GF}_{\mathrm{LE}}$ determines the computable aspects of the correlation between the SF and PF of complex expressions. Second, there are systematic dependencies both within and among these components, organizing the configurations of primitive elements in PF $F_{L E}, F_{L E}$, and the sub-components of $\mathrm{GF}_{\mathrm{LE}}$. The specific constraints which in this sense determine the configurations permitted as possible lexical entries are in part given by UG - for example the semantically determined canonical hierarchy of Argument Positions as indicated in (16) - and in part by language particular conditions, such as the Case assignment for directional prepositions sketched in (22b).

An obvious consequence of these observations is the fact that on the one hand the information listed in lexical entries is idiosyncratic, hence conventional and susceptible to historical change, while on the other hand, by no means every alternative collection of basic elements could be listed as a lexical entry.

A less obvious, and possibly more interesting consequence of these considerations is the fact that there are different types of idiosyncrasy or irregularity. Let me illustrate this point by a simple example. According to the previous discussion, we would have the follwoing entries for the German prepositions in (in/into), bei (near), and $z u$ (to/towards), where [ PROX $\mathrm{x}$ ] selects the proximal and [ INT $\mathrm{x}$ ] the internal environment of $x$ :

$$
\begin{aligned}
& \text { / bei / }[-\mathrm{V},-\mathrm{N}] \quad \lambda \mathrm{x} \quad \lambda y \quad[\quad \mathrm{y} \operatorname{LOC}[\mathrm{PROX} x]] \\
& / \text { in } / \quad[-\mathrm{V},-\mathrm{N}] \quad \lambda \mathrm{x} \quad \lambda \mathrm{y} \quad[\text { (FIN) y LOC [ INT } \mathrm{x}]] \\
& / \mathrm{zu} / \quad[-\mathrm{V},-\mathrm{N}] \underset{[+\mathrm{Obl}]}{\lambda x} \lambda \mathrm{y} \quad[\text { FIN y LOC [PROX } \mathrm{x}]]
\end{aligned}
$$

By general assumption, all information listed in these entries is idiosyncratic, i.e. it does not follow from general conditions. ${ }^{44)}$ Thus, that bei begins with a voiced labial stop (and not e.g. a voiceless fricative) and selects the proximal rather than e.g. the vertical environment of the relatum is unpredictable in just this sense. Also, the fact that (76) collapses two items (due to the optionality of FIN), while (75) and (77) are single items, is an idiosyncratic property. What I want to emphasize, however, is the following. (75) and (76) do not specify Case information, as this follows from Structural Case Assignment for prepositions according to (57c), providing Dativ for (75) as well as for the locative variant of (76). Furthermore the directional variant of (76) receives Accusative by (22b). Because of this general condition on German prepositions, however, (77) must provide the idiosyncratic condition [+Obl], which would be the predictable Case, if $z u$ were not a directional preposition. Thus, even though $z u$ assigns the default Case of prepositions, the Dative is an irregularity, as it comes with the semantic condition of directionality. To put it the other way round, if the general condition (22b) were dropped, $z u$ would become a fully regular preposition that would not have to be lexically marked, in order to assign Dative. ${ }^{45)}$ Finally, prepositions like während (during), trotz (inspite of) are idiosyncratically marked for Genitive - irrespective of condition (22b). Thus, even with respect to an apparently simple phenomenon like objective Case of prepositions, three types of idiosyncrasy can be distinguished - depending on the intervening general conditions. 
Other cases illustrating the same sort of distinctions could easily be adduced.

This leads to a more general remark on the nature of lexical information from a minimalist perspective. The requirement of optimal, i.e. redundancy free, coding of lexical entries is directly related to the rules and principles organizing the representation of lexical information. According to the Minimalist Program, these rules and principles should not depend on (i) arbitrary stipulations, and (ii) specific conditions of individual languages - except in rather restricted, presumably parameter dependent ways. In order to clarify (ii), let us consider the following general schema:

$$
\text { I-Language }
$$

Lexical System R-P I

$$
\text { Set of Entries R-P II }
$$

This schema expresses the notion that a given I-Language is determined by certain Rules or Principles, R-P I, and its Lexical System, which in turn consists of the set of lexical entries and certain Rules and Principles II. Put this way, the tension between the two conceptions of lexical information mentioned earlier can be ascribed to the distinction between the Lexical System, and the Set of Entries, where the latter, though determined by R-P II, contains all and only the 'irregularities' of the language. There are now a number of possibilities concerning the status of R-P II and its relation to R-P I:

(79) (a) Both R-P I and R-P II apply equally to lexical entries and complex expressions, such that there would be no distinction between them.

(b) There are Rules or Principles R-P II that apply within the Lexical System, but not outside of it.

(c) R-P I consists exclusively of Principles defined by UG, while language specific Rules must belong to R-P II.

I want to conclude this discussion with some remarks related to these distinctions, which do not, of course, exhaust the conceivable possibilities.

First, it should be obvious that the options (79)(a) to (c) make increasingly specific claims about the organization of I-Language. ${ }^{46)}$ Assuming that e.g. conditions on the organization of Argument Structure must apply within the Lexical System in the sense that their effect must be fixed, before lexical entries enter a 'Numeration' in the sense of Chomsky (1995), from which complex expressions are constructed, I will adopt (79b). Assuming furthermore that the construction of complex expressions from a Numeration is determined by only universal principles, suggests that we adopt (79c). In other words, we do have a system R-P II that operates inside the Lexical System, and that language specific rules belong to this system. This does not imply, however, that general principles of R-P I do not control the organization of lexical information.

Second, (79c) does not mean that R-P II consists of only language particular rules, including the idiosyncrasies of morphology, or the specific conditions on Case 
assignment, etc. Notice, incidentally, that it is by no means obvious in advance that conditions that refer to language specific choices - like morphological Case, Gender, or Number - cannot be based on universal patterns as suggested e.g. in footnote 37 with respect to Abstract Case. In other words, even Principles that determine strictly intra-lexical properties of I-Language may belong to UG directly, even though language specific implementation of Principles of UG might be the characteristic situation in R-P II. For the sake of illustration, consider the principles we have used in order to collapse different lexical items into one entry. These principles rely on general conditions on disjunctive ordering (the so-called "elsewhere-condition"), accompanied by Boolean conditions on selected feature values or components. Thus the mechanisms on which this aspect of economy relies are universal, but furnished with language specific options. This might ultimately hold also for rules and patterns of inflectional morphology, as Wunderlich (1992 and this volume) illustrates in interesting ways.

Third, as a consequence of these considerations, even the set of lexical entries ceases to be an unstructured list, it rather exhibits systematic internal organization. One aspect of this organization might be the layers envisaged in Lexical Morphology and Phonology as initiated by Kiparsky (1982). Another aspect concerns the distinction between basic and complex items, major lexical and functional categories, stems and affixes, to mention the more obvious distinctions.

Even though there are various alternatives to be explored, the assumption that lexical information is subject to economizing principles that properly belong to the Lexical System should be taken as an indispensible ingredient of the minimalist perspective.

\section{Footnotes}

1) Chomsky refers to A-P and C-I as performance systems. This might be misleading if one relates it to the terminology that distinguishes between competence and performance in the sense of e g. Chomsky (1965). As a matter of fact, structures in A-P, and even more so in C-I, are subject to tacit or implicit knowledge (in the sense of pertinent competence), on which the relevant performance may be based. In other words, the term 'performance system' must be understood as merely fixing the perspective, where I-language recruits patterns in A-P and C-I to implement linguistic expressions, without denying their respective knowledge systems.

2) It is an empirical point which modality of perception and production P-A relies on. While for clearly non-incidental reasons auditory perception and articulation are the canonical implementation of P-A, it is important to note that sign languages show the accessibility of the visual modality as a primary choice (not - like writing - based on spoken language). For the role of linearity in sign language see e.g. Sandler (1989).

3) It seems to me worth noticing that this schema closely matches basic assumptions made e.g. in Hjelmslev (1961), where Form and Substance are distinguished for both the Content- and Expression-Plane, which can be schematized in the following way: 
Substance $<===>$ Form ------ Form <===> Substance

Expression- and Content-Substance correspond to A-P and C-I, respectively, the respective Forms to PF and LF. Hjelmslev considers the relation between Form and Substance as manifestation, assuming that a given Form can manifest itself in different ways (and different substances, for that matter). The obvious similarity between (1) and (i) might be taken to indicate that we are indeed facing conceptual necessities.

4) See Bierwisch (1996) for further comments on the notion that a level of representation might be used by two (or more) mental systems, such that e.g. PF might be considered as a specific aspect of a representational system recruiting configurations of A-P, subject to the conditions or operations imposed by $G$. Alternatively, PF (or LF, for that matter), is to be construed as a level of representation of its own, that needs to be related to configurations of A-P (or C-I) by specific correspondence rules or principles. The latter view is advocated by Jackendoff (1994) as the concept of representational modularity, considering a module as a level of representation.

5) One might, with Bickerton (1995), consider the lexicon not just as a conceptual necessity of language, but as a factual prerequisite of its phylogenetic development, arguing that the gradual expansion of lexical knowledge is a byproduct (or even a driving force) in the phylogenetic brain growth. On this view, the characteristic property of the (pre-linguistic) phase of Proto-Language is the capacity to associate fixed configurations of two mental domains.

6) As a matter of fact, the availability of discrete infinity might, according to considerations of Chomsky (1988), be taken as the crucial property that constitutes the language capacity - together perhaps with the capacity for arithmetic. More specifically the application of this capacity to a body of lexical knowledge might be the „big bang“ of Bickerton (1995) or Pinker (1994), by which the evolution created the human linguistic capacity.

7) For some discussion of PF representations along these lines see e.g. Clements (1985) or Sagey (1986). It might be noted that the layers of organization - features arranged in tiers, segments, syllables - seem to be invariant with respect to modality. As e.g. Sandler (1989) and Perlmutter (1992) show, American Sign Language exhibits essentially the same type of organization - which is, of course, an empirical observation, not a conceptual necessity. In what follows, I will not be concerned with details of PF and indicate representations simply by alphabetic spelling.

8) Although various versions of categorial or type systems are used in formal, model theoretic semantics, I do not want to commit myself to model theoretic semantics in any formal sense.

9) The interpretability of elements is not always obvious. For the sake of illustration, consider the phonetic interpretation of standard orthography, where the distinction 
between different letters as a rule receives a phonetic value, while the distinction of capitals vs. lower case letters does not, and the status of space is unclear in this respect. Notice also that spacing as well as the use of capitals appears to be economical with regard to the computation involved in reading.

10) Notice incidentally that the assumption of phonological derivations raises the question of intermediate representations going beyond schema (1), a not at all trivial issue, which I will not take up here. See also note 26 for a similar problem at the semantic side.

11) To mention just two: first, as is well known, (8a) and (8b) are not really synonymous - put on the shelf is less specific than shelve, an issue that was intensively discussed with respect to similar proposals in the Generative Semantics framework. See e.g. Fodor (1970) for critical remarks. (It might be noted, incidentally, that there is a remarkable similarity between certain tenets of the LRS-approach and the proposals of Generative Semantics.) Second, Hale and Keyser consider it as an argument in favor of their analysis, that, inspite of the existence of particle verbs like take over etc., there is no shelve on or bottle in, because their derivation would violate the ECP, constraining Head Movement. Notice, however, that exactly this type of verbs is rather productive in German: aus-grenzen (cause NP to be outside the boundary), ein-kleiden (put NP in clothes), ein-tüten (put NP into bags), and many others. Even English would, on this analysis, violate the ECP in verbs like fence NP in.

12) It would not be appropriate, by the way, to simply assume that LCS, belonging to CS, is outside I-Language, so that Jackendoff's Syntactic Structure would correspond to LF as the only level of syntactic representation. This is by no means just a terminological issue, even though some of the problems involved are not easily assigned to one or the other domain, the syntactic or semantic treatment of binding being a case in point.

13) It should be emphasized for terminological reasons that by "semantics“ I have in mind the conceptual and intentional interpretation of linguistic expressions, i.e. an internalist, not a reference based (model theoretic) semantics. If one includes this internalist semantics into the realm of syntax because of its necessarily representational character, one would presumably have to conclude with Chomsky (1995a) that natural language has only syntax and pragmatics. This leaves us, however, with the necessary distinction between the combinatorial aspects of conceptual structure as opposed to the compositional properties of linguistic expressions, depending on I-Language. In other words, I take semantics as the interpretation in C-I, as envisaged in the Minimalist Program.

14) This is actually the gist of categorial systems as used e.g. in Cresswell (1973), Steedman (1989) and related work, where syntactic categories are in fact identified with semantic types.

15) Features for which conceptual interpretation is rather unlikely, are those defining structural Case like Nominative, Accusative, Absolutive, etc, as opposed to notional Case like Locative, Allative, Elative, etc., although the Localistic Theory of Case proposes abstract spatial interpretation even for Cases like Nominative, Accusative, see e.g. Hjelmslev (1935/1937) for detailed discussion. Somewhat different 
considerations apply to what Bech (1955) called Status as a verbal category, which includes Infinitive and Participle.

16) Whether the moving or the target feature is associated with conceptual content need not concern us here, as I will propose a slightly different way to look at the checking metaphor below.

17) Thus SHELF is not really a unit of type 1 - the type of individuals, but rather a one-plcace predicate, i.e. of type $0 / 1$. What we would need in a more explicit account, is something like (i), where $g$ represents something like the canonical or generic carrier of the property SHELF:

\section{(i) $\quad\left[\begin{array}{lll}\mathrm{y} & \mathrm{ON} & \mathrm{g}\end{array}\right] \&\left[\begin{array}{lll}\text { SHELF } & \mathrm{g}\end{array}\right]$}

This restriction to the 'canonical shelf' might be related to the more specific interpretation of shelve as opposed to put on the shelf mentioned in note 11).

18) This does not exclude, incidentally, the possibility of improper argument positions whithout semantic content, technically speaking lambda operators that don't bind a variable. Thus the subject of so called weather verbs is not semantically licensed. More complex cases are verbs like es handelt sich um NP (it is the question of NP), where both es and sich are improper arguments. Those cases are highly restricted in several respects, though.

19) This can be taken as a generalization of Case-marking as assumed in Chomsky (1981), where Case-assignment (rather than eliminating by checking) was construed as the prerequisite for an argument to successfully combine with its head. The generalization concerns the fact that formal features in general, rather than merely Case features, might be involved in the relevant condition.

20) One might, by the way, assume that the association of c-features with lambda operators is mediated by functional heads such as AGR(eement), T(ense), etc. If [Acc] in (18) should in fact be dependent on AGR-O, the lexical entry of the functional head would be something like (i) with empty PF:

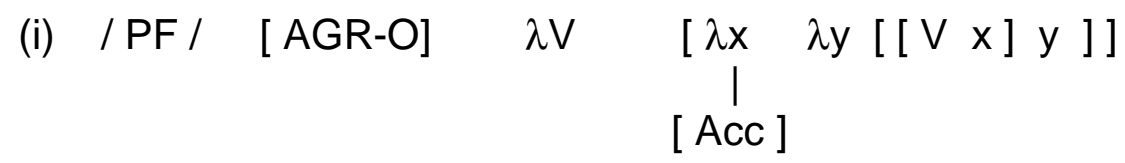

I will not go into technical details, assuming rather that minimalist conditions should prevent empty categories where possible, as suggested in Chomsky (1995).

21) Actually, the effect of the functor FIN is slightly more complex, as it must assign to its argument the structure of a path in order to pick out the final part or goal of the path. I will take this to be the automatic consequence of the interpretation of [FIN x] in C-I, where the interpretation of $x$ determines the character of the path it creates. See Bierwisch (1988) for details.

22) Whether or not directional and locative prepositions and adverbials are to be categorized by the feature [+Dir(ectional)] and [-Dir], respectively, depends on a number of problems I cannot pursue here. See Bierwisch (1988) for some 
discussion. In case [ ${ }_{+}$Dir] is in fact a formal feature categorizing syntactic constituents, it would belong to those that are fairly transparent with respect to their semantic correspondent and conceputal interpretation. We could express this relation by a lexical condition of the following sort:

(i) [FIN x] and [INIT x] imply [+Dir] in the categorization of $[-\mathrm{N},-\mathrm{V}]$ entries, if $\mathrm{x}$ is bound by the highest Argument Position.

The component [INIT(ial part of) $\mathrm{x}$ ] includes source-prepositions like aus (out of), von (from), which are grammatically directional. Condition (i) is certainly in need of modification in several respects, it is merely meant here as an indication of the generalization relevant to the interpretation of [+Dir].

23) For discussion of a formal semantics of DO and CAUSE see Dowty (1979). The construal of propositions as sets of events or states can be made precise in various ways. The event-instantiation ' $e$ ' introduced in (23c) will be related below to the $E$ position considered in Higginbotham (1985) and related work.

24) This can be made precise by means of a three-valued logic in ways that I will not pursue here. It might be noted, though, that NOT[ $p: q]$ should come out as equivalent to $p$ : NOT $q$, both having the truth-value of NOT $q$, iff $p$ is true, being undefined otherwise.

25) This does not exclude the possibility that presupposition is a heterogeneous phenomenon to which various sources besides lexical information contribute. See e.g. Choon-Kyu and Dinneen (1979) for an early, extensive discussion of different approaches to the problem. I need not go here into the ramified issues, but simply take for granted that change-of-state verbs introduce a lexical presupposition of the kind illustrated by cases like (28).

26) Like the principles compensating for underspecification in PF, definitions like those in (24) would have to be understood as principles deriving complete interface representations from redundancy free lexical information. As for PF, the question of intermediate levels of representation arises, as mentioned in note 10.

27) This cannot be the whole story yet, however, because as it stands (37) is less complex than (36), which is contrary to fact: The optional causativity of open, clear, fix, etc. is clearly the more frequent, more neutral property, compared to the obligatory causativity of clean. There is an obvious desideratum, which I will not pursue here.

28) The notion of a Referential Theta-role was first proposed in Williams (1981), where it was construed on a par with roles like Agent, Experiencer, Theme, etc., i.e. as characterizing the content of an Argument Position. It was obvious right from the beginning, though, that a rather different aspect is at issue here, as the Referential role of nouns like perceiver, percept, employer and employee is that of Experiencer, Theme, Agent and Patent, respectively. In other words, what defines the content of an Argument Position as Agent, Goal, Experiencer, etc. is independent from its status as Referential. Similar comments apply to the distinction of Internal and External Position or Role. 
29) This observation, which might be in need of some refinements, has sometimes led to the claim that Nouns generally don't take complements, but only adjuncts (or something in between called complement-adjuncts). See e.g. Grimshaw (1990) for arguments to that effect. In view of the fact that optional arguments and modifiers might not necessarily be distinct under certain conditions, as I have argued in Bierwisch (1988), the essence of complement-adjuncts might simply be the status of optional Argument Positions.

30) The Referential Position of Verbs thus corresponds to the E-position proposed in Higginbotham (1985).

31) For further discussion of event-nominalizations that essentially switch the syntactic categorization of a verb to that of a noun see Bierwisch (1990) where the consequences of this switch are spelled out in more detail.

32) Alternative proposals to specify syntactic category features have been made repeatedly. See e.g. Jackendoff (1977), or the discussion of Wunderlich and Steinitz, summarized from a typological point of view in Steinitz (1995).

33) One obvious point of language particular variation concerns the exploitation of the category features: Languages need not distinguish the four categories assumed here. See the references in note 32 for some discussion.

34) It might be noted, incidentally, that frieren can also be used as a weather-verb in constructions like es friert (it's freezing), which requires an entry analogous to that of the verb rain mentioned earlier:

(i) $/$ frier / $[+\mathrm{V},-\mathrm{N}] \quad \lambda \mathrm{x} \quad \lambda \mathrm{e} \quad$ [e INST [ COLD ] ]

By means of the notational conventions already mentioned, (i) could be collapsed with (51) as shown in (ii):

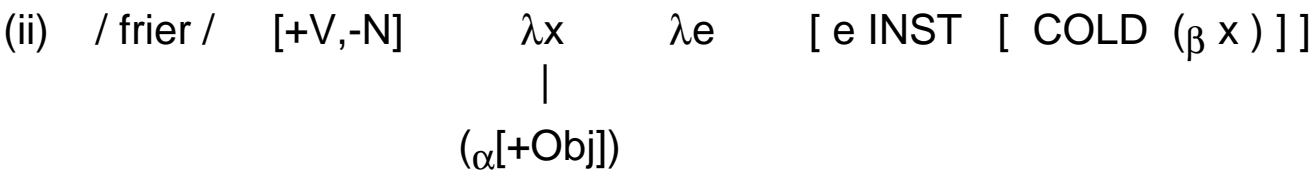

Condition: If $\beta=-$, then $\alpha=-$.

For $\beta=-$, COLD must be a proposition, like RAIN, turning $\lambda x$ into an improper argument, which is subject to general constraints on improper argument positions. There are various problems to be clarified, which I cannot pursue here any further.

35) ASK is, of course, an abbreviation with roughly the following definition:

(i) $[[A S K x] y] z==$ DEF $z$ DO-CAUSE [y KNOW [ $z$ WANT [ $z$ KNOW $x$ ]] ]

As (i) shows more clearly, $\lambda z$ is the Agent, $\lambda x$ the Theme, and $\lambda y$ the Recipient or Addressee of the act of asking. This is not intended as a complete account of fragen, but only as a provisional characterization of the s-selection associated with it. 
36) The notion of modification and of referential binding inherent in these considerations is largely that of Higginbotham (1985). See also Bierwisch (1988).

37) The notion of Abstract Case as proposed by Kiparsky (1993) and adapted in Wunderlich (1994) might be a step in this direction. Kiparsky suggests that abstract Case features might simply derive from the place of an argument position in the Argument Structure of a verb, such that for verbs with one, two, and three structural arguments the configurations in (i), (ii), and (iii), respectively, emerge (using Wunderlichs features 'Ir' meaning „there is a lower role“, and 'hr' meaning „there is a higher role"):

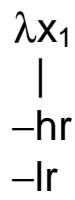

(ii)

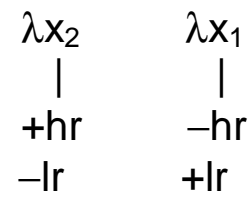

(iii)

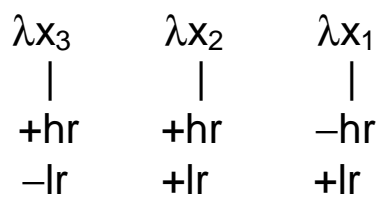

These abstract Case features are realized by morphological Case according to language particular specifications, which would for German be as follows:

$\begin{array}{lccc} & \text { Nom } & \text { Acc } & \text { Dat } \\ \mathrm{hr} & - & + & + \\ \mathrm{lr} & - & - & +\end{array}$

Under these conditions, language particular specifications would be completely reduced to morphologiocal features and their realization, while conditions on Structural Case underlying (i) to (iii) are completely universal. One interesting consequence of this approach is the fact that it might explain the restriction of Argument Structure to maximally three structural positions: The configurations (i) to (iii) exhaust the possibilities that can be distinguished by means of the abstract features $\mathrm{hr}$ and Ir. Even though these proposals account for a number of interesting facts, I will leave it at that, as it is not clear at present how it can account for Case of complements of nouns, adjectives, and prepositions in non-trivial ways.

38) Notice that the generalization expressed in (22) for Case of locative vs. directional prepositions interlocks structural Dative and lexical Accusative, related to the pertinent condition in SF.

39) The notion of derivational economy requires Move to be restricted to cases where its application is indispensible. Even though these cases belong to the very core of natural languages, the position of the finite verb in Germanic languages being a case in point, I will not go into the controversial details to be observed in this connection. The effects of Merge discussed here must be considered as a prerequisite in any case.

40) In Chomsky (1995) it is proposed to consider the complete lexical information of a lexical head $X$ as its characteristic properties $X$ ', avoiding the issue as to what exactly constitutes the X' of a lexical unit X. The operation Spell Out, however, that separates PF information from the rest has to sort out the features of $X$ into various components, anyway. Hence given the rich structure of LE motivated here, I will stick 
to the traditional notion that a lexical item projects its categorization in terms of formal features. We will encounter additional motivation for this assumption shortly.

41) That is in fact the proposal developed in Chomsky (1995), where Adjunction is supposed to lead to a categorization that identifies the result of Merge as composed of segments. Gaertner (1995) discusses some of the problems that emerge from this assumption, which seems to me dispensible, if adjunction is characterized by the manner in which the Argument Position of the adjunct is discharged, as proposed e.g. in Higginbotham (1985). I will turn to this alternative immediately.

42) Intuitively, the SF representation of (74) is derived by discharging the object position $\lambda x$ of open, replacing the variable $x$ by $x^{i}$ and adjoining the precondition [DEF $x^{i}\left[\right.$ DOOR $x^{i}$ ] ] to the SF of open. I will not go into the formal details of this operation here.

43) A detailed discussion of the formal features of C-elements of German and English can be found in Wilder (1995), accounting especially for the intra-clausal effects of different complementizers. What needs to be developed is an analysis of both the formal and semantic properties of different C-elements which account for their properties as heads not only of main clauses, but also of various types of complement clauses, as in

(i) I know that/whether he will come

(ii) I know who one should ask

(iii) I know where to go/who to ask

44) It should be obvious that further general conditions would reduce the information that must be specified in these and other cases discussed earlier. Suppose, for instance, that the normal Argument Structure of a preposition requires exactly two obligatory positions, then the indication of $\lambda x$ and $\lambda y$ in (75) to (77) would have to be dropped. Similar considerations apply throughout. What I am trying to clarify here is the nature and consequence of general conditions, not their actual content for a particular set of lexical entries.

45) It is worth noticing that these distinctions would change in detail, but not in principle, if (57c) would be changed such that Accusative becomes the Structural Case for the object of prepositions, and (22b) would assign [+Obl] in case FIN is absent, rather than [-Obl], if FIN is present.

46) As a matter of fact, the two dimensions underlying these distinctions, namely intra- vs. extra-lexical conditions, and language specific vs. universal conditions, are independent of each other. More specifically, the assumption of extra-lexical, language specific rules is not only logically possible, but has been taken for granted at least until the Principles- and Parameter-Theory was introduced in Chomsky (1981).

\section{References}

Ajdukiewicz, Kazimierz (1935) Über die syntaktische Konnexität, Studia Philosophica 1, 1-27 
Archangeli, Diana (1984) Underspecification in Yawelmani Phonology and Morphology, Doctoral dissertation MIT, Cambridge, Mass.

Barwise, Ion and Robin Cooper (1981) Generalized Quantifiers and Natural Language, Linguistics and Philosophy, 4, 159-219

Bech, Gunnar (1955) Studien über das deutsche Verbum infinitum, 1. Band, Munksgaard, Copenhagen

Bickerton, Derek (1995) Language and Human Behavior, University of Washignton Press, Seattle

Bierwisch, Manfred (1987) A Structural Paradox in Lexical Knowledge, in: Eike van der Meer and Joachim Hoffmann (eds.) Knowledge Aided Information Processing, 141-172, Elsevier, Dordrecht

Bierwisch, Manfred (1988) On the Grammar of Local Prepositions, in: Studia Grammatica 29, 1-65

Bierwisch, Manfred (1990) Event Nominalization: Proposals and Problems, Acta Linguistica Hungarica 40, 19-84

Bierwisch, Manfred (1996) How much space gets into language? in: Bloom, Petersen, Nadel, Garrett (eds.) Language and Space, MIT-Press, Cambridge, Mass.

Chomsky, Noam (1957) Syntactic Structures, Mouton, S'Gravenhage

Chomsky, Noam (1965) Aspects of the Theory of Syntax, MIT-Press, Cambridge, Mass.

Chomsky, Noam (1975) The Logical Structure of Linguistic Theory, Plenum Press New York

Chomsky, Noam (1981) Lectures on Government and Binding, Foris, Dordrecht

Chomsky, Noam (1986) Knowledge of Language: Its Nature, Origin, and Use Praeger, New York

Chomsky, Noam (1988) Language and Problems of Knowledge, MIT-Press, Cambridge, Mass.

Chomsky, Noam (1991) Some notes on economy of derivation and representation, in: Robert Freidin (ed.) Principles and Parameters in Comparative Grammar, MIT Press, Cambridge, Mass.

Chomsky, Noam (1993) A Minimalist Program for Linguistic Theory, in: Kenneth Hale and Samuel Jay Keyser (eds.) The View from Building 20, 1-52, MIT Press, Cambridge, Mass.

Chomsky, Noam (1995) The Minimalist Program, MIT-Press, Cambridge, Mass 
Chomsky, Noam (1995a) Language and Nature, Mind 104, 1-59

Chomsky, Noam and Morris Halle (1968) The Sound Pattern of English, Harper and Row, New York

Choon-Kyu Oh and David A. Dineen, eds. (1979) Presupposition: Syntax and Semantics, Vol. 11, Academic Press, New York

Clements, George N. (1985) The Geometry Phonological Features, in: C.J. Ewan and J. M. Anderson (eds.) Phonology Yearbook 2, 225-252, Cambridge University Press, Cambridge

Cresswell, Max J. (1973) Logics and Languages, Methuen \& Co, London

Dowty, David R. (1979) Word Meaning and Montague Grammar, Reidel, Dordrecht

Farkas, Donka (1990) Two Cases of Underspecification in Morphology, Linguistic Inquiry 21, 539-550

Fodor, Jerry A. (1970) Three Reasons for Not Deriving „Kill“ from „Cause to Die“, Linguistic Inquiry 1, 429-438

Gaertner, Hans Martin (1995) Has Bare Phrase Structure superseded X-Bar Theory? in: FAS Papers in Linguistics 4, 22-35, Berlin

Grimshaw, Jane (1990) Argument Structure, MIT-Press, Cambridge, Mass.

Hale, Kenneth and Samuel Jay Keyser (1993) On Argument Structure and the Lexical Expression of Syntactic Relations, in: Kenneth Hale and Samuel Jay Keyser (eds) The View from Building 20, 53-109, MIT-Press, Cambridge, Mass.

Halle, Morris (1959) The Sound Pattern of Russian, Mouton, S'Gravenhage

Halle, Morris and Alec Marantz (1993) Distributed Morphology and the Pieces of Inflection, in: Kenneth Hale and Samuel Jay Keyser (eds.) The View from Building 20, 111-176, MIT-Press, Cambridge, Mass.

Higginbotham, James (1985) On Semantics, Linguistic Inquiry 16, 547-593

Hjelmslev, Louis (1935/1937) La Categorie des Cas, I. et II. Partie, Universitetsforlaget, Aarhus

Hjelmslev, Louis (1961) Prolegomena to a Theory of Language, The University of Wisconsin Press, Madison

Jackendoff, Ray S. (1977) X Bar Syntax: A Study of Phrase Structure, MIT-Press, Cambridge, Mass.

Jackendoff, Ray S. (1990) Semantic Structures, MIT-Press, Cambridge, Mass 
Jackendoff, Ray S. (1994) Lexical Insertion in a Post-minimalist Theory of Grammar, Ms., Brandeis University

Kean, Mary-Louise (1975) The Theory of Markedness in Generative Grammar, unpublished doctoral dissertation, MIT

Kean, Mary-Louise (1981) On a Theory of Markedness, in: Belletti, Brandi, Rizzi (eds.) Theory of Markedness in Generative Grammar, 559- 604, Scuola Normale Superiore di Pisa, Pisa

Kiparsky, Paul (1982) Lexical Morphology and Phonology, in: I.S. Yang (ed) Linguistics in the Morning Calm, 3-91, Hanshin, Seoul

Kiparsky, Paul (1992) Structural Case, Ms. Stanford

Levelt, Willem J. M. (1989) Speaking. From Intention to Articulation, MIT-Press, Cambridge, Mass.

Perlmutter, David (1992) Sonority and Syllable Struct ure in American Sign Language, Linguistic Inquiry 23, 407-442

Pesetsky, David (1985) Morphology and Logical Form, Linguistic Inquiry 16, 193-246

Pinker, Steven (1994) The Language Instinct, William Morrow and Comp., New York

Pustejovski, James (1995) The Generative Lexicon, MIT-Press, Cambridge, Mass.

Sagey, Elizabeth C. (1986) The Representation of features and Relations in Non-Linear Phonology, Doctoral dissertation, MIT

Sandler, Wendy (1989) Phonological Representation of the Sign: Linearity and Nonlinearity in American Sign Language, Foris, Dordrecht

Steedman, Mark (1989) Constituency and Coordination in a Combinatory Grammar, in: Mark Baltin and Anthony Kroch (eds.) Alternative Conceptions of Phrase Structure, 201-231, The University of Chicago Press, Chicago

Steinitz, Renate (1995) Towards a revision of the lexical subcategorization features, FAS Papers in Linguistics 1, Berlin, 101-116

Steriade, Donka (1987) Redundant Values, in:Anna Bosch, Barabara Need, Eric Schiller (eds.) Papers from the 23rd Annual Regional Meeting, Part Two, 339-362, Chicago Linguistic Society, Chicago

Wilder, Christopher (1995) Derivational Economy and the Analysis of V2, in: FAS Papers in Linguistics 1, 117-156, Berlin

Williams, Edwin S. (1981) Argument Structure and Morphology, Linguistic Review 1, 81-114 
Wunderlich, Dieter (1991) How do prepositional phrases fit into compositional syntax and semantics? Linguistics 29, 591-621

Wunderlich, Dieter (1992) A Minimalist Analysis of German Verb Morphology, SFBPapiere Theorie des Lexikons, 21 Universität Düsseldorf

Wunderlich, Dieter (1994) CAUSE and the Structure of Verbs, SFB-Papiere Theorie des Lexikons, 36 Universität Düsseldorf 